$1 / x$

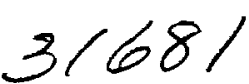

NASA Contractor Report 187163

AIAA-91-2342

036

\title{
Applied-Field MPD Thruster Geometry Effects
}

Roger M. Myers

Sverdrup Technology, Inc.

Lewis Research Center Group

Brook Park, Ohio

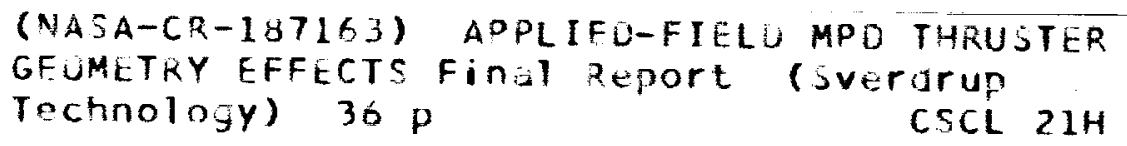

Unclas

0031681

August 1991

Prepared for

Lewis Research Center

Under Contract NAS3-25266 
$=\quad$.

.

. 


\title{
Applied-Field MPD Thruster Geometry Effects
}

\author{
Roger M. Myers ${ }^{1}$ \\ Sverdrup Technology, Inc. \\ NASA Lewis Research Center Group \\ Brook Park, OH 44142
}

\begin{abstract}
Eight MPD thruster configurations were used to study the effects of applied-field strength, propellant, and facility pressure on thruster performance. Vacuum facility background pressures higher than $\sim 0.12 \mathrm{~Pa}$ were found to significantly influence thruster performance and electrode power deposition. Thrust efficiency and specific impulse increased monotonically with increasing applied field strength. Both cathode and anode radii fundamentally influenced the efficiency-specific impulse relationship, while their lengths influenced only the magnitude of the applied magnetic field required to reach a given performance level. At a given specific impulse, large electrode radii result in lower efficiencies for the operating conditions studied. For all test conditions, anode power deposition was the largest efficiency loss, and represented between $50 \%$ and $80 \%$ of the input power. The fraction of the input power deposited into the anode decreased with increasing applied field and anode radius. The highest performance measured, $20 \%$ efficiency at 3700 seconds specific impulse, was obtained using hydrogen propellant.
\end{abstract}

\section{Nomenclature}

$\begin{array}{ll}B, B_{z} & \begin{array}{l}\text { magnetic field strength, } T \\ \text { discharge current, } A\end{array} \\ J_{d} & \begin{array}{l}\text { anode and cathode lengths, cm } \\ L_{a}, L_{c}\end{array} \\ h & \text { mass flow rate, } g / s \\ R_{a}, R_{c} & \text { anode and cathode radii, cm } \\ T & \text { thrust, } N \\ V_{a n} & \text { effective anode fall, } V \\ V_{d} & \text { discharge voltage, } V \\ \phi & \text { anode work function, } V\end{array}$

'Propulsion Engineer, member AIAA 


\section{Introduction}

Magnetoplasmadynamic (MPD) thrusters have demonstrated performance levels and power handling capabilities of interest for application to Earth orbit, unmanned planetary, cargo, and piloted missions. For MPD thrusters to successfully compete with conventional chemical propulsion systems, the thrusters will typically require power-to-thrust conversion efficiencies greater than $40 \%$ at specific impulses over 4000 seconds with the thrusters operating at power levels over one megawatt. The required total impulses for missions to the moon and Mars range from $1 \times 10^{8}$ to $1 \times 10^{9} \mathrm{~N}$-s. To date, MPD thrusters have been operated continuously at power levels over $500 \mathrm{Kw}$ at $\sim 20 \%$ efficiency and 1500 seconds specific impulse, or in a quasisteady-state mode (with durations $\sim 1$ millisecond) at powers of several megawatts with efficiencies up to $40 \%$ and 5000 seconds specific impulse'. The maximum demonstrated total impulse is $1 \times 10^{6} \mathrm{~N}$-s. These thrusters have been tested with and without externally applied magnetic fields, and the applied-field thrusters have consistently shown better performance than those that rely solely on the self-induced magnetic field. While several authors have made this observation ${ }^{2,3}$ there is currently neither a fundamental understanding of applied-field MPD thruster performance nor a systematic data base from which to derive empirical scaling laws. Furthermore, it is critical that such a data base be established to use for model verification. The purpose of this work was to address this issue by testing several thruster geometries in a systematic fashion over a wide range of operating conditions.

A typical MPD thruster, shown in Fig. 1, consists of a central cathode with a coaxial annular anode. Propellant, injected through an insulating boron nitride plate at the rear of the chamber, is heated, ionized, and accelerated to high velocity via the interaction of the discharge current passing between anode and cathode and either the self-induced or externally applied magnetic field. The thruster power balance is usually dominated by the thrust power, unrecovered power used to heat and ionize the propellant, and the power deposited into the anode, with cathode power and radiation losses representing only a small fraction of the input power. The discharge voltage is determined by the ohmic dissipation, back EMF, and the electrode fall voltages, where the latter play a dominant role in establishing the power deposited into the electrodes. Self-field thrusters must be operated at very high current levels (over $10 \mathrm{kA}$ ) for the ohmic and back EMF terms to dominate the electrode falls and thus enable deposition of most of the power into the accelerating plasma. For self-field thrusters operated at lower currents the electrode falls dominate the discharge voltage, so that most of the discharge power is deposited into the electrodes. Applied-field thrusters mitigate this problem by introducing another back EMF term to Ohm's Law and decreasing the plasma conductivity, both of which increase the discharge voltage. However, by itself, increasing the discharge voltage is insufficient to improve the thruster performance, since the additional energy deposited into the plasma must be converted into thrust power. Experimental studies have shown that both these phenomena, an increase in discharge voltage and enhanced thrust, occur with most applied-field thrusters. However, it is not possible from the available data to determine performance limits for these thrusters or even establish what geometries and 
operating conditions are associated with improved performance. Correlations between the life-limiting mechanisms and performance have not been addressed at all.

Facility limitations suggest that for the foreseeable future continuous MPD thruster testing will be limited to power levels below about one megawatt. This dictates the establishment of both an empirical data base and verified numerical models to permit rational extrapolation to higher power levels. This requires both high fidelity thruster performance evaluation and establishment of scaling laws in terms of fundamental parameters.

This paper presents the results of performance measurements made on eight MPD thruster electrode configurations run on argon and hydrogen propellants at power levels between 50 and $150 \mathrm{~kW}$. The thruster geometries and operating conditions were chosen so as to permit, as far as possible, isolation of the effects of the individual geometric parameters. Following a discussion of the thruster designs and experimental facility, the results of the performance and power balance measurements are presented, including measurements made at several facility pressures. The implications of these results for applied-field MPD thruster scaling are then discussed in the context of existing theoretical models for these thrusters. Finally, a summary of the major conclusions from this work is presented.

\section{Experimental Apparatus}

\section{Thruster and Applied Field Magnet Designs}

Several thruster geometries were tested with and without applied magnetic fields. A typical thruster, shown schematically in Fig. 1, consisted of a cylindrical copper anode with a coaxial, $2 \%$ thoriated tungsten cathode. Both electrodes were water cooled, the anode via a passage in its wall, the cathode by conduction through a water cooled copper cathode clamp. A boron nitride backplate was used to inject propellant through holes located near the midradius between anode and cathode and through an annulus at the cathode base. The dimensions of the anode and cathode geometries tested are given in Table 1. The cathode used for geometry $\mathrm{G}$ had a conical tip, for all other geometries the cathode tip was hemispherical. In addition to the cylindrical anodes (geometries A - G in Table 1), a test was performed using a $7.62 \mathrm{~cm}$ long flared anode. The flared anode had a $2.5 \mathrm{~cm}$ upstream diameter and a $5.1 \mathrm{~cm}$ radius exit plane with an expansion angle of 33 degrees. The dimensions of the flared anode thruster (geometry $\mathrm{H}$ ) were chosen to permit direct comparison with the $2.5 \mathrm{~cm}$ and $5.1 \mathrm{~cm}$ radius straight cylinder anodes.

The MPD thrusters were mounted inside solenoidal coils used to generate the applied magnetic fields. Two coil sizes were needed to accomodate the various thruster geometries and maximize the potential applied field. The first, with a bore diameter of $15.3 \mathrm{~cm}$ and a length of $15.3 \mathrm{~cm}$, consisted of 36 turns of $1.3 \mathrm{~cm}$ diameter copper tubing; it was used for tests of geometries A, B, and G. The second, with a bore diameter of $20.3 \mathrm{~cm}$ and length of 
$15.3 \mathrm{~cm}$, was made using 28 turns of $1.9 \mathrm{~cm}$ diameter copper tubing; it was used for tests of geometries $\mathrm{C}-\mathrm{F}$ and $\mathrm{H}$. For all tests described in this report the thrusters were mounted such that the anode exit plane was flush with the end of the solenoid. The axial field strengths were measured as a function of magnet current and checked for symmetry. These calibrations yielded axial field strengths of $1.66 \times 10^{-4} \mathrm{~T} / \mathrm{A}$ and $8.48 \times 10^{-5} \mathrm{~T} / \mathrm{A}$ at the centerline of the magnet exit plane for the 15.3 and $20.3 \mathrm{~cm}$ magnets, respectively. The solenoidal field shapes are discussed in Ref. 4. All field strengths reported below correspond to the field value at the centerline of the magnet exit plane.

\section{Vacuum Facility, Power, and Propellant Management Systems}

The MPD thruster test stand, shown in Fig. 2, was mounted inside a $3 \mathrm{~m}$ diameter test chamber separated from the main $7.6 \mathrm{~m}$ diameter, $21 \mathrm{~m}$ long tank by a $3 \mathrm{~m}$ diameter gate valve. The main tank was pumped by twenty $0.9 \mathrm{~m}$ diameter oil diffusion pumps backed by three roots blowers and two roughing pumps. This facility maintained a backpressure below $0.07 \mathrm{~Pa}\left(5 \times 10^{-4}\right.$ Torr) at argon flow rates below $0.16 \mathrm{~g} / \mathrm{s}$, or hydrogen flow rates below $0.030 \mathrm{~g} / \mathrm{s}$.

The thruster power supply consisted of a series-parallel network of six $65 \mathrm{~kW}$ arc welding supplies. This network, which supplied up to $3000 \mathrm{~A}$ at $130 \mathrm{~V}$, was electrically isolated from ground. A single $65 \mathrm{~kW}$ welding supply provided up to $1500 \mathrm{~A}$ to the appliedfield magnet. The thruster was ignited using a $2 \mathrm{~kW} 900 \mathrm{~V}$ direct-current supply which was attached to the thruster electrodes in parallel with the main power system. Diodes protected the main power supply from the high voltage of the igniter. The welding supplies had substantial ripple, the magnitude of which varied slightly with thruster geometry and operating condition. Typical thruster discharge current and voltage traces sampled at $2 \mathrm{kHz}$ are shown in Fig. 3. These were obtained using thruster geometry $G$ at an applied magnetic field strength of $0.182 \mathrm{~T}$ and a discharge current of $750 \mathrm{~A}$. The ripple was $\sim 20 \%$ at a frequency of $\sim 600 \mathrm{~Hz}$ for both the discharge current and voltage.

The thruster and applied field magnet were water cooled using separate closed loop heat exchangers, each providing up to $0.47 \mathrm{~V} / \mathrm{s}$ of distilled water. Two smaller heat exchangers provided up to $0.1 \mathrm{l} / \mathrm{s}$ of water to cool various diagnostic systems in the facility. Domestic water was used to cool parts of the facility located close to the test stand.

Propellant was fed to the thruster using two independent flow paths. This permitted changes in the thruster propellant distribution and the gradual mixing of up to three propellants using a series of valved cross lines between the two flow paths. Propellant flow rates were measured using thermal conductivity type flow controllers with $2 \%$ precision. A constant volume calibration system connected in series with the thrusters was used periodically to obtain an absolute measure of the gauge accuracy for all propellants tested. These calibrations showed that the propellant flow rate was accurate to within 3\%. The propellant feed system had the capability to provide a fast pulse of $\sim 100 \mathrm{kPa}$ gas to the chamber during discharge ignition. This was accomplished by providing a gas line which ran directly 
to the thruster and bypassed the flow meters. The gas pulse was fired using a solenoid valve located inside the tank next to the thruster.

\section{Performance and Power Balance Measurements}

The thrust stand, described in Ref. 5, consisted of an inverted pendulum with an oscillation damping circuit, remote leveling apparatus and an in situ calibration mechanism. The leveling mechanism was used to compensate for tank distortions during pump down and for the different masses and centers of gravity of the various thruster configurations. The motor driven calibration mechanism consisted of three $1.52 \mathrm{~N}$ weights which were suspended from the thruster using a pulley. The influence of the applied-field magnet on the thrust measurement was checked before and after each test. In addition, an extensive series of tests were performed with various shorting bar configurations mounted on the thrust stand to study the influence of the discharge current on the thrust measurement, including one in which the cooling water temperature was raised to over $66^{\circ} \mathrm{C}$ to simulate the effects of high power thruster operation on the current conducting flexures. In none of these tests did the tares exceed an equivalent force of $0.01 \mathrm{~N}$, or approximately $1 \%$ of the typical thrust levels. However, extended ( $>2 \mathrm{hr}$ ) thruster operation at powers over $100 \mathrm{~kW}$ could introduce zero shifts of up to $0.1 \mathrm{~N}$. This forced periodic repetition of the initial operating point of an extended test throughout the test duration. Comparisons of the offsets observed in this fashion and that measured after termination showed good agreement, and reduced the experimental error to less than $3 \%$.

The total heat transfer to the anode and the heat conducted into the cathode base were measured calorimetrically by monitoring the cooling water temperature rise and flow rate. The temperature rise was measured using type $\mathrm{K}$ thermocouples imbedded a minimum of 10 $\mathrm{cm}$ into the flow tubes. The water flow rate was determined using turbine flow meters. Both these measurements were calibrated several times during the course of the experiments, the water flow rates were accurate to within $2 \%$ and the temperatures to $+/-0.5^{\circ} \mathrm{C}$. To maintain the measurement accuracy within $5 \%$, the water flow rate was periodically adjusted such that the temperature rise was over $10^{\circ} \mathrm{C}$.

Thruster performance was monitored in several ways. All voltages, currents, propellant flow rates, and temperatures were continuously displayed on a set of panel meters and simultaneously fed into a computerized data acquisition system. The digital system could be used in three modes, including automatic recording of a full set of data at a specified time interval, ranging from 1 second to 2 minutes, recording a single data set in response to a key stroke, or recording 200 full data sets at $2 \mathrm{kHz}$. The latter mode was used to check current and voltage ripple and record transients. All instrumentation was calibrated periodically. Voltage and current measurements were accurate to within $1 \%$. 


\section{Experimental Procedure}

Thruster performance was characterized in terms of thrust efficiency, $\eta$, and specific impulse, $I_{s p}$, defined by:

$$
\eta=\frac{T^{2}}{2 V_{d d} J_{d}^{\dot{m}}} ; I_{s p}=\frac{T}{\dot{m} g_{0}}
$$

from which it is clear that measurements of thrust, discharge voltage and current, and propellant flow rate were required. No effort was made in this work to subtract cold flow thrust or to include the applied-field magnet power in the calculations. The latter was justified on the basis that the magnet power can be dramatically reduced via a simple redesign of the coils.

As discussed in detail below, anode power deposition was by far the dominant loss for all operating conditions. Typically, between $50 \%$ and $80 \%$ of the input power was deposited into the anode, while less than $5 \%$ was either conducted up the cathode base or radiated from the cathode surface. It has been shown previously that for argon propellant the convective and radiative terms of the anode power balance are small, leading to the power deposition equation ${ }^{6}$ :

$$
P_{a}=J_{e}\left(V_{a n}+\frac{5 k T_{e}}{2 e}+\phi\right)
$$

The first term in this equation represents the contribution of the anode fall voltage, the second represents the thermal energy of the incoming electrons, and the third represents the contribution of the anode material work function. Note the fall voltage in this context is not the sheath voltage, but rather is a term which describes the directed energy of the electrons when they hit the anode surface. In this work the electron temperature inside the chamber was not measured, so it was not possible to isolate the effects of the anode fall. However, Gallimore ${ }^{9}$ showed that for tests using argon propellant the dominant contribution to the anode power came from the anode fall voltage, and that the relative contributions of the terms did not change dramatically with increasing applied field strength. This evidence notwithstanding, in this work the "effective anode fall voltage" was calculated by dividing the anode power by the discharge current.

Each test began by presetting the mass flow rate and allowing the tank background pressure to stabilize. The applied field magnet was then turned on and a set of countdown timers were used to activate the main power supply, fire the gas pulse (if necessary), and turn on the high voltage igniter in a preset sequence. A color video camera was used to monitor and record all tests. The ignition phase was usually characterized by some particulate ejection, though this ended within one to three seconds if the thruster was operating properly. 
Once the discharge had stabilized, data collection began. The thruster was allowed to remain at a given operating point for a few minutes before a data set was taken, and each measurement was taken several times to ensure repeatability. An attempt was made to determine the stable operating envelope for each thruster geometry, though this was precluded in several cases by the limited cooling capacity of the thruster water heat exchanger. For most geometries, operation was attempted at propellant flow rates of $0.05,0.1$, and $0.14 \mathrm{~g} / \mathrm{s}$ argon, discharge currents of 750,1000,1500, and 2000 amps, and magnetic field strengths, measured at the centerline of the magnet exit plane, between 0 and 0.2 Tesla. For all tests, weight loss measurements of the cathode and boron nitride backplate were used to establish an upper bound on the erosion rates and their contribution to the propellant stream. This contribution never exceeded $0.5 \%$ of the injected flow. While some anode erosion was evident with the large radius thrusters, it was impossible to quantify due to the large mass of the anode and the limited resolution of the weight balance.

\section{Thruster Performance and Power Balance}

In the following sections the effect of facility pressure, thruster geometry, and propellant species are discussed. For all thrusters used in this study turning the magnetic field off resulted in unstable operation characterized by particulate emission. As discussed in Ref. 4, it appears that this results from a decrease in the cathode surface temperature with decreasing applied-field strength and the resulting inability of the cathode to emit the discharge current in a diffuse fashion. This paper does not address the impact of discharge current, propellant flow rate, or injection scheme on thruster performance. Throughout, an attempt was made to establish the scaling relationships needed to improve thruster performance.

\section{Effect of Facility Background Pressure}

Of critical importance in experimental MPD thruster work is the influence of the facility pressure on the measurements. Sovey and Mantenieks ${ }^{1}$, in their review of past MPD thruster work, showed that the facility pressure had to be less than $0.07 \mathrm{~Pa}\left(5 \times 10^{-4} \mathrm{~T}\right)$ to avoid affecting the performance measurements. However, it was impossible to assess how this requirement changed with thruster configuration and operating condition. For instance, research at the University of Stuttgart indicated that for nozzle type self-field thrusters operated at high mass flow rates with argon, the facility pressure has no impact below approximately $5 \mathrm{~Pa}\left(4 \times 10^{-2} \mathrm{~T}\right)^{7}$. At present there is only a very limited understanding of the mechanisms by which ambient gas influences the performance and power balance of MPD thrusters, which means that the effects should be verified with each device. This places unreasonable constraints on the experimental program, which forces selection of geometries 
and operating conditions where the sensitivity to backpressure is high. With this in mind, a test was performed with geometry $C$ with an argon propellant flow rate of $0.1 \mathrm{~g} / \mathrm{s}$, a discharge current of $1500 \mathrm{~A}$, and an applied field strength of $0.021 \mathrm{~T}$. Thruster performance at the lowest available tank pressure was 1750 seconds at $13 \%$ efficiency. After running stably at this condition for approximately 15 minutes the diffusion pumps were turned off. The tank pressure started to rise approximately 10 minutes later. As shown in Figures $4-7$, the tank pressure had a dramatic effect on all thruster parameters, including thrust, discharge voltage, and the effective anode fall voltage. Negligible effects were evident until approximately 0.12 $\mathrm{Pa}\left(9 \times 10^{-4}\right.$ Torr $)$, though above this all measured parameters decreased sharply with increasing pressure. For the pressure range studied, the thrust dropped over $15 \%$, from $1.7 \mathrm{~N}$ to $1.3 \mathrm{~N}$, and the discharge voltage dropped $\sim 25 \%$, from $80 \mathrm{~V}$ to $60 \mathrm{~V}$. The slight minima observed at $\sim 4 \mathrm{~Pa}\left(3 \times 10^{-2}\right.$ Torr $)$ in the thrust led to a corresponding sharp increase in the measured efficiency, as shown in Fig. 6. It is important to note that the decrease in the effective anode fall voltage corresponds closely to the decrease in the discharge voltage (Fig. 7), which suggests that the drop in discharge voltage was due in part to a reduction in the anode fall. This result indicates that ambient gas entrainment at high pressure may play a dominant role in the anode fall region.

\section{Influence of Thruster Geometry}

\section{Anode Radius}

Changing the anode radius and shape had large effects on the terminal voltage, specific impulse and efficiency, as shown in Figures $8-10$. The thrusters used for these tests were geometries $\mathrm{A}, \mathrm{B}, \mathrm{C}$, and $\mathrm{H}$, from Table $\mathrm{L}$. All data shown were taken with an argon flow rate of $0.1 \mathrm{~g} / \mathrm{s}$ at a discharge current of $1000 \mathrm{~A}$. The large scatter in the terminal voltage observed at low applied magnetic field strengths with geometry B was due to changes in the anode power deposition (see below). The terminal voltage, specific impulse, and efficiency increased nearly linearly with applied-field strength, up to a maximum performance which was limited by the capacity of the thruster water cooling. The highest efficiency for these operating conditions was $23 \%$, and was measured with the smallest radius cylindrical anode (geometry A). The maximum measured specific impulse for these operating conditions was approximately 1800 seconds for all thrusters. Listed in Table 2 are the slopes of the linear least-squares fits to the data. The rates of increase of all three performance parameters with applied-field strength increased approximately quadratically with anode radius for the cylindrical thrusters. The flared anode thruster slopes were close to the $2.5 \mathrm{~cm}$ radius anode, geometry A, for the voltage and between those for geometry A and B for the specific impulse. These differences are reflected in the efficiency - specific impulse characteristics, shown in Fig. 11, where the flared anode thruster has the highest slope and the three cylindrical geometries all have similar, though lower, slopes.

The effects of applied-field strength and anode radius on anode power deposition and the effective anode fall are shown in Figures 12 and 13. It is clear that the anode power fraction decreases with both increasing applied-field strength and with increasing anode 
radius. The anode power fraction of the flared anode geometry was closest to that for the largest cylindrical thruster, geometry $\mathrm{C}$, and appears to fall more rapidly with increasing applied field than that for the cylindrical thrusters. This is reflected in the behavior of the effective anode fall voltage (Fig. 13) which appears to increase linearly with the applied field for all geometries. The large scatter for geometry B was directly reflected in the discharge voltage, but did not appear to influence the thrust. The effective anode fall for the flared anode thruster had the lowest dependence on the applied field strengths.

Note that while the anode power fraction is smallest with the largest radius thruster, for the operating conditions shown the thrust efficiency is highest with the smallest radius thruster (Fig. 10). This shows that the efficiency with which power deposited into the plasma is converted to thrust is significantly higher with the smaller thruster.

\section{Anode Length}

The effect of anode length was tested with the $5.1 \mathrm{~cm}$ radius cylindrical anode using lengths of 7.6 and $15.2 \mathrm{~cm}$ (geometries $E$ and F). As shown in Figures $14-16$, doubling the anode length reduced the thruster voltage, specific impulse, and efficiency, but did not significantly influence the rate of change of these parameters with the magnetic field. The changes in magnitude were very large, with the $15.2 \mathrm{~cm}$ long anode yielding results $15 \%$ to $30 \%$ below those of the $7.6 \mathrm{~cm}$ long anode. The impact of these changes on the efficiency specific impulse characteristic are shown in Fig. 17, where it is seen that while the two geometries lie on the same overall curve, data taken with the longer anode appears only in the lower ranges of efficiency and specific impulse. Thus, it appears that anode length does not have the same fundamental influence as the anode radius, though it does affect the applied field required to achieve a given performance level.

Figures 18 and 19 show the effect of anode length and applied field strength on the anode power fraction and the effective anode fall voltage. The longer anode consistently showed about $10 \%$ higher anode power fraction and $5 \mathrm{~V}$ higher effective fall voltage. The anode length did not significantly change the rate of increase of the effective fall voltage with the applied field strength. Note that in large part the change in anode power fraction explains the difference in thrust efficiencies. While this presumes that other losses are constant, the quantitative agreement observed across the range of field strengths indicates that the dominant reason for the change in efficiency was an increase in the anode loss with the longer anode.

\section{Cathode Radius}

As shown in Fig. 20 the cathode radius had little effect on the voltage magnitude and only a slight effect on its rate of increase with magnetic field. The latter effect was observed at other discharge currents, which indicates that the effect was real. The voltage increased from approximately $60 \mathrm{~V}$ at $0.03 \mathrm{~T}$ with both cathode geometries to over $100 \mathrm{~V}$ at high field strength. The upper applied field limit with the $0.64 \mathrm{~cm}$ diameter cathode, geometry $\mathrm{C}$, was reached at an applied field strength of $0.065 \mathrm{~T}$, when sparks were observed coming out of the 
chamber. No such phenomena were observed with the larger cathode, for which the upper limit was due to the magnet power supply. The cathode radius had a large effect on the specific impulse and efficiency, as shown in Figures 21 and 22, with the $0.64 \mathrm{~cm}$ radius cathode yielding much higher specific impulses and correspondingly higher efficiencies. In fact, the slope of the least-squares fit to both parameters appears to be inversely proportional to the cathode radius. Plotting the efficiency - specific impulse characteristic (Fig. 23) shows that the smaller radius cathode had a higher magnitude and a modestly higher slope than the larger cathode.

The anode power fraction, shown as a function of magnetic field strength in Fig. 24, was $\sim 10 \%$ lower for the small radius cathode. It is evident from Fig. 25, however, that the effective anode fall voltage was the same for these two geometries, so that the difference in power fraction is due solely to an increase in the voltage across the plasma.

\section{Cathode Length}

The short cathode used for this study, geometry $G$, had a conical tip and was $2.5 \mathrm{~cm}$ long. It is clear from Fig. 26 that cathode length had no effect on the discharge voltage, which increased from $\sim 40 \mathrm{~V}$ at low applied field strength to $\sim 115 \mathrm{~V}$ at the higher fields. However, the specific impulse and efficiency, shown in Figures 27 and 28, were higher with the short cathode thruster, though their rate of increase with magnetic field was lower than with the long cathode thruster. The maximum specific impulse and efficiency, 2300 seconds at $23 \%$, were measured with the short cathode thruster. It is clear from the efficiency specific impulse characteristic shown in Fig. 29, however, that changing the cathode length did not affect the shape of this curve, though the long cathode data was restricted to the lower ranges of efficiency and specific impulse.

Reducing the cathode length reduced the anode power fraction by $\sim 25 \%$. Figure 30 shows that while the anode power fraction decreased rapidly from about $72 \%$ to $60 \%$ for the long cathode, it never exceeded $52 \%$ for the short cathode. While there is substantial scatter in the effective anode fall data at low applied fields shown in Figure 31, it is clear that the rate of increase of the effective anode fall voltage was the same for both cathode geometries, though its magnitude was approximately $6 \mathrm{~V}$ higher with the long cathode. In contrast to the case with the anode length, the difference in thrust efficiencies for the two cathode lengths cannot be explained solely on the basis of changes in the anode power fraction. For example, at a field strength of $0.12 \mathrm{~T}$ the anode power fraction is $25 \%$ less with the short cathode thruster, but the thrust efficiency is only $\sim 10 \%$ higher. It is clear that other loss mechanisms change when the cathode length is changed.

The effect of cathode length could not be correlated with the ratio of $\mathrm{L}_{a} / \mathrm{L}_{c}$, since the anode length studies described above showed that extending the anode made performance worse. As described in Ref. 6 shortening the cathode had a dramatic effect on the plume characteristics - which was not observed when the anode length was increased. It is possible the observations described here are a result of the combined effects of shortening the cathode 
and changing the tip shape to a cone. These changes may both increase the current emission from the tip and improve the flow field around it. These effects are further discussed in Ref. 4.

\section{Influence of the Propellant}

The influence of propellant species was studied by comparing tests run with hydrogen and argon at the same mass flow rate. The facility pumping limits required that this study be done at a mass flow rate of $0.025 \mathrm{~g} / \mathrm{s}$, since this was the highest hydrogen flow rate for which the tank background pressure could be maintained below $0.07 \mathrm{~Pa}$. This in turn forced the use of geometry $\mathrm{A}$, with a straight $2.5 \mathrm{~cm}$ radius anode, since it was the only thruster that operated stably with this low an argon mass flow rate. Figures 32 - 35 show that all performance parameters for a given applied field strength are much higher with hydrogen than argon, with the discharge voltage increasing by $10-20 \mathrm{~V}$, the specific impulse by just under 1000 seconds, and the efficiency almost doubling. The highest measured performance was 3700 seconds specific impulse at $20 \%$ efficiency. The efficiency - specific impulse characteristic shown in Fig. 35 reemphasizes these differences, and shows that the slope of this characteristic was not affected by the change in propellant. This result is particularly interesting in light of the dramatic change in the behavior of the anode power fraction shown in Fig. 36 for this test case. At the very low flow rate used in this test, $0.025 \mathrm{~g} / \mathrm{s}$, the anode power fraction for argon actually increases with increasing applied field strength, in sharp contrast to the results for higher argon flow rates (discussed above) and those for hydrogen shown in the figure. The effective anode fall results shown in Fig. 37 reiterate the observed differences, with the hydrogen results starting at a slightly higher fall voltage but increasing at a much slower rate than those for argon. Note that direct comparison of the effective anode fall voltages for argon and hydrogen is difficult because convective heat transfer almost certainly plays a larger role with hydrogen than with argon.

\section{Scaling Relationships}

The above data were used to establish the dependencies of the thruster performance parameters on thruster geometry. Partial derivatives of voltage and thrust with respect to applied field strength were obtained from the data to extract the functional forms of these relationships. The result for thrust was

$$
T \propto \frac{R_{a}^{2}}{k_{1} L_{c} R_{c}} B+k_{2} f\left(L_{a}\right)
$$

where the second term simply indicates that while the thrust depended on the anode length, 
the length had no effect on the influence of the magnetic field. For the terminal voltage the result was

$$
V \propto \frac{R_{a}^{2}}{k_{3} R_{c}} B+k_{4} f\left(L_{a}\right)
$$

where again the second term represents the impact of the electrode lengths. In these relationships $k_{1}, k_{2}, k_{3}$, and $k_{4}$ are constants. The only known analytic model for applied field MPD thruster plasma acceleration is that of Fradkin ${ }^{8}$. In that work, relations are derived for the thrust and plasma potential drop as functions of applied field strength and thruster geometry. The complexity of the problem dictated use of the following assumptions:

1. The dominant acceleration was due to the recovery of azimuthal momentum.

2. The plasma was confined to the magnetic flux tube emanating from the anode.

3. The plasma rotated as a solid body

4. Negligible viscosity

Note that contributions due to the self-magnetic field, pressure forces, and azimuthal currents interacting with the radial magnetic field were neglected. Neglect of self-field terms was easily justified for the test conditions in this work (discharge currents $\sim 1000 \mathrm{~A}$ ), but neglect of thermal acceleration and azimuthal current terms relied on assumed plasma properties (ion temperature and density gradients) for which there was little supporting data. The results of the model were:

$$
T=\frac{1}{\sqrt{2}} B J_{d} R_{a}\left[1-\frac{3}{2}\left(\frac{R_{c}}{R_{a}}\right)^{2}\right]
$$

and

$$
V_{d}=V_{c}+\frac{B^{2} J_{d} R_{a}^{2}}{2 \dot{m}}
$$

where $V_{c}$ is the voltage drop due to ohmic heating and the electrode falls. The model correctly predicted the experimentally observed linear dependence of thrust on magnetic field strength and the quadratic increase in discharge voltage with anode radius. However, it is clear that for the operating conditions studied in this work the thrust increased quadratically, not linearly, with anode radius, and the discharge voltage increased linearly, not quadratically, with applied field strength. In addition, the model dependence on cathode radius is very weak, in contrast to the experimental results. While the measured effect of anode length may be a result of viscous effects, which were neglected in the model, it appears the cathode length plays a different role since it affected both the magnitude and the rate of thrust increase with applied field. It is not clear, at present, which of the model assumptions breaks down for the operating conditions used in this work, and clearly this should be a focus of future work. Furthermore, to accurately compare the analytical model with experimental results it is necessary to isolate the voltage drop across the plasma from the total discharge 
voltage: the scaling of the anode fall voltage may preclude accurate comparisons until this is done. At present the absence of electron temperature measurements close to the anode prevent accurate assessments of the anode fall voltage and limit work to studies of the effective anode fall.

The effective anode fall voltage increased linearly with applied field strength for all geometries. The only geometric parameters which altered the slope of the effective fall voltage vs. applied field were the anode radius and shape, though it was not possible to establish a quantitative dependence. The effective fall voltage increased slightly with anode length and decreased with decreasing cathode length. It was independent of cathode radius.

A tentative explanation for the scaling of the effective anode fall voltage was advanced previously in Ref. 9. In that work it was shown that the electron Hall parameters near the anode are between 10 and 100 , and that the electron gyro radius can become comparable to the Debye length for field strengths used in these experiments. The decrease in plasma density associated with larger thruster sizes may be the cause of the observed anode radius dependence. A decrease in plasma density would result in an increased electron Hall parameter and decrease the rate of cross-field diffusion to the anode, requiring a higher electric field at the anode to conduct the discharge current. The comparison between hydrogen and argon supports this argument, since the greater number densities associated with hydrogen at a given flow rate would reduce the Hall parameter. The observed slow increase of the effective fall voltage with applied field strength with the flared anode thruster may be due to the intersection of the anode surface with the magnetic field lines. This would permit current carrying electrons to travel along field lines into the anode, reducing the requirement for cross-field conduction near the anode.

\section{Conclusions}

Eight applied-field MPD thruster geometries were used to establish the dependence of thruster performance on geometric scale, applied field strength, propellant, and facility background pressure. Anode and cathode radii and lengths were varied over a factor of two for a range of operating conditions. Efficiency and specific impulse were found to increase approximately linearly with applied-field strength. For a given mass flow rate and discharge current, hydrogen propellant yielded significantly better performance than argon. The highest performance, $20 \%$ efficiency at 3700 seconds specific impulse, was obtained with hydrogen propellant at the maximum achievable applied field. For all test conditions the largest thruster power sink was the anode, which consumed between $50 \%$ and $80 \%$ of the input power. For the geometries and operating conditions studied, both thrust and discharge voltage increased linearly with applied-field strength, quadratically with anode radius, and decreased with increasing cathode radius. The thrust also decreased with increasing cathode and anode length, though the latter did not affect the thrust vs. applied-magnetic field slope. The 
voltage was independent of cathode length, but increased with decreasing anode length. These results showed that only the electrode radii have a fundamental impact on the efficiency - specific impulse curve, with smaller radius electrodes having higher efficiencies at a given specific impulse for the operating conditions studied. The observed scaling with electrode radii for applied-field thrusters was very different than that for self-field thrusters, for which thrust scales as $\ln \left(R_{a} / R_{c}\right)$. The electrode lengths merely changed the required applied field strength the achieve the desired performance. Facility pressures above $0.12 \mathrm{~Pa}$ ( $9 \times 10^{-4}$ Torr) had a large impact on thruster performance and anode power deposition. Thrust and discharge voltage first decreased with increasing facility pressure, then the thrust increased slightly as the pressure approached $4 \mathrm{~Pa}$. The decrease in discharge voltage with increasing pressure was strongly correlated with a decrease in anode fall voltage.

\section{Acknowledgements}

The author would like to thank John Naglowsky, Larry Schultz, John Eckert, Tom Ralys, David Wolford, John McAlea, Rob Butler, John Miller, Gerry Schneider, Cliff Schroeder, David Wehrle, and Shawn Reese for their invaluable assistance during this project.

\section{References}

1. Sovey, J. and Mantenieks, M., "Performance and Lifetime Assessment of MPD Arc Thruster Technology," Journal of Propulsion and Power, Vol. 7, No. 1, Jan - Feb. 1991, pp. $71-83$.

2. Tahara, $\bar{H}$., Yasui, H., Kagaya, Y., and Yoshikawa, T., "Development of a Quasi-Steady MPD Arcjet Thruster For Near-Earth Missions," AIAA Paper 87-1001, May 1987.

3. Kagaya, Y., Yoshikawa, T., and Tahara, H., "Quasi-Steady MPD Arcjets with Applied Magnetic Fields," AIAA Paper 85-2001, Oct. 1985.

4. Myers, R.M., Wehrle, D., Vernyi, M., Biaglow, J. and Reese, S., "Applied Field MPD Thruster Plume Characteristics," AIAA Paper 91-2339, June 1991.

5. Haag, T., "Design of a Thrust Stand for High Power Electric Propulsion Devices," AIAA Paper 89-2829, NASA TM 102372, July 1989.

6. Saber, A. J., and Jahn, R.G., "Anode Power Deposition in Quasi-Steady MPD Arcs," AIAA Paper 73-1091, Oct. 1973.

7. Kurtz, H.L, Auweter-Kurtz, M., and Schrade, H.O., "Self-Field MPD Thruster Design Experimental and Theoretical Considerations," AIAA Paper 85-2002, Oct. 1985.

8. Fradkin, D. B., Blackstock, A.W., Roehling, D. J., Stratton, T., Williams, M., and Lieweter, K. W., "Experiments using a 25-kW Hollow Cathode Lithium Vapor MPD Arcjet," AIAA Journal, Vol. 8, No. 5, May 1970, pp. 886-894.

9. Myers, R. M., Mantenieks, M., and Sovey, J., "Geometric Effects in Applied Field MPD Thrusters," AIAA Paper 90-2669, NASA TM 103259, July 1990. 


\begin{tabular}{|c|c|c|c|c||}
\hline Geometry & $\begin{array}{c}\text { Anode Radius } \\
\mathrm{Ra}, \mathrm{cm}\end{array}$ & $\begin{array}{c}\text { Anode Length } \\
\text { Lc, } \mathrm{cm}\end{array}$ & $\begin{array}{c}\text { Cathode Radius } \\
\mathrm{Rc}, \mathrm{cm}\end{array}$ & $\begin{array}{c}\text { Cathode } \\
\text { Length, Lc, cm }\end{array}$ \\
\hline \hline A & 2.5 & 7.6 & 0.64 & 7.6 \\
\hline B & 3.81 & 7.6 & 0.64 & 7.6 \\
\hline C & 5.1 & 7.6 & 0.64 & 7.6 \\
\hline D & 5.1 & 15.2 & 0.64 & 7.6 \\
\hline E & 5.1 & 7.6 & 1.27 & 7.6 \\
\hline F & 5.1 & 15.2 & 1.27 & 7.6 \\
\hline G & 3.81 & 7.6 & 0.64 & 2.5 \\
\hline H & $\begin{array}{c}2.5-5.1 \\
\text { (Flared) }\end{array}$ & 7.6 & 0.64 & 7.6 \\
\hline
\end{tabular}

Table 1: Dimensions of the MPD thrusters.

\begin{tabular}{|c|c|c|c|c||}
\hline Geometry & $\begin{array}{c}\text { Voltage vs. Bz, } \\
\text { slope (V/Tesla) }\end{array}$ & $\begin{array}{c}\text { Isp vs. Bz slope } \\
\text { (S/Tesla) }\end{array}$ & $\begin{array}{c}\text { efficiency vs Bz } \\
\text { slope } \\
\left.\text { (Tesla }^{-1}\right)\end{array}$ & $\begin{array}{c}\text { Efficiency vs. } \\
\mathrm{I}_{\text {sp }} \text { slope }^{\left(\mathrm{sec}^{-1}\right)}\end{array}$ \\
\hline \hline A & 254 & 6171 & 0.60 & $9.76 \times 10^{-5}$ \\
\hline B & 569 & 13275 & 1.43 & $1.08 \times 10^{-4}$ \\
\hline C & 1141 & 22120 & 2.07 & $9.35 \times 10^{-5}$ \\
\hline H & 291 & 9185 & 1.30 & $1.41 \times 10^{-4}$ \\
\hline
\end{tabular}

Table 2: Least-squares slopes for efficiency, Isp and Voltage vs. applied field for four anode geometries. 


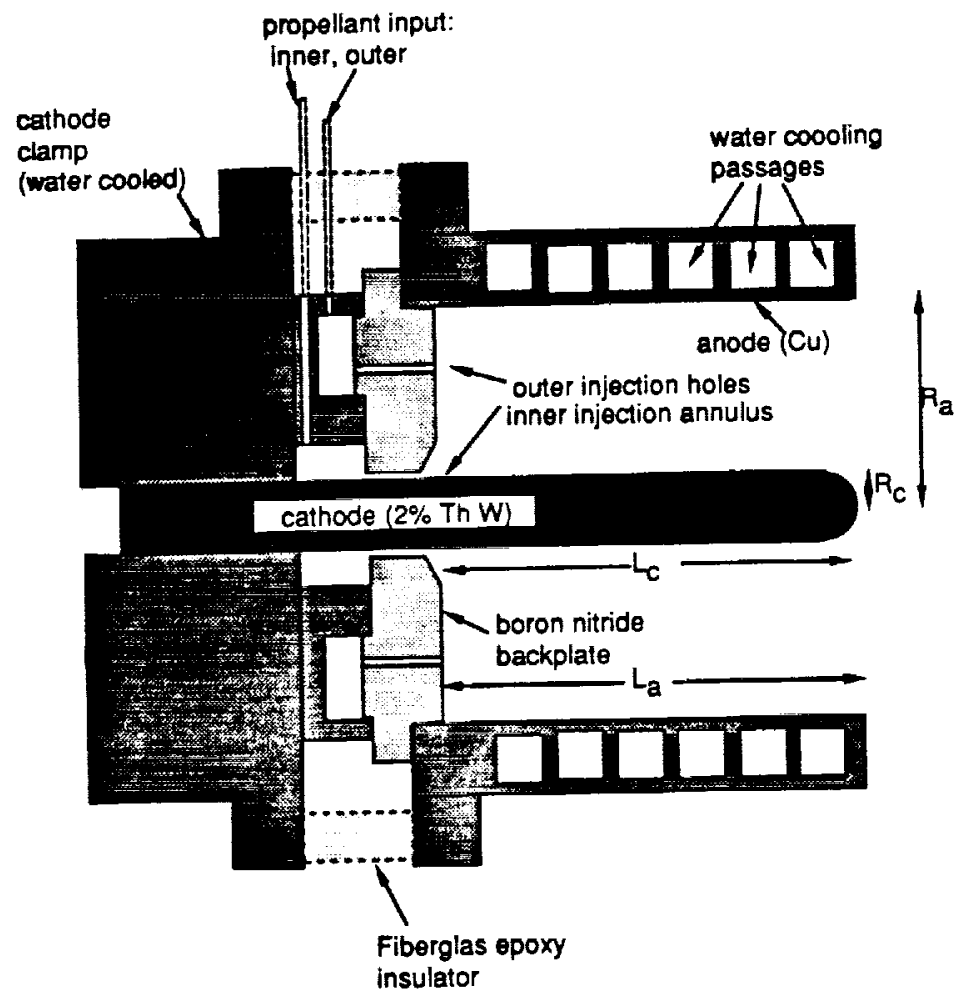

Figure 1. MPD thruster schematic. Applied field magnet not shown. Electrode dimensions are given in Table 1. Not to scale.

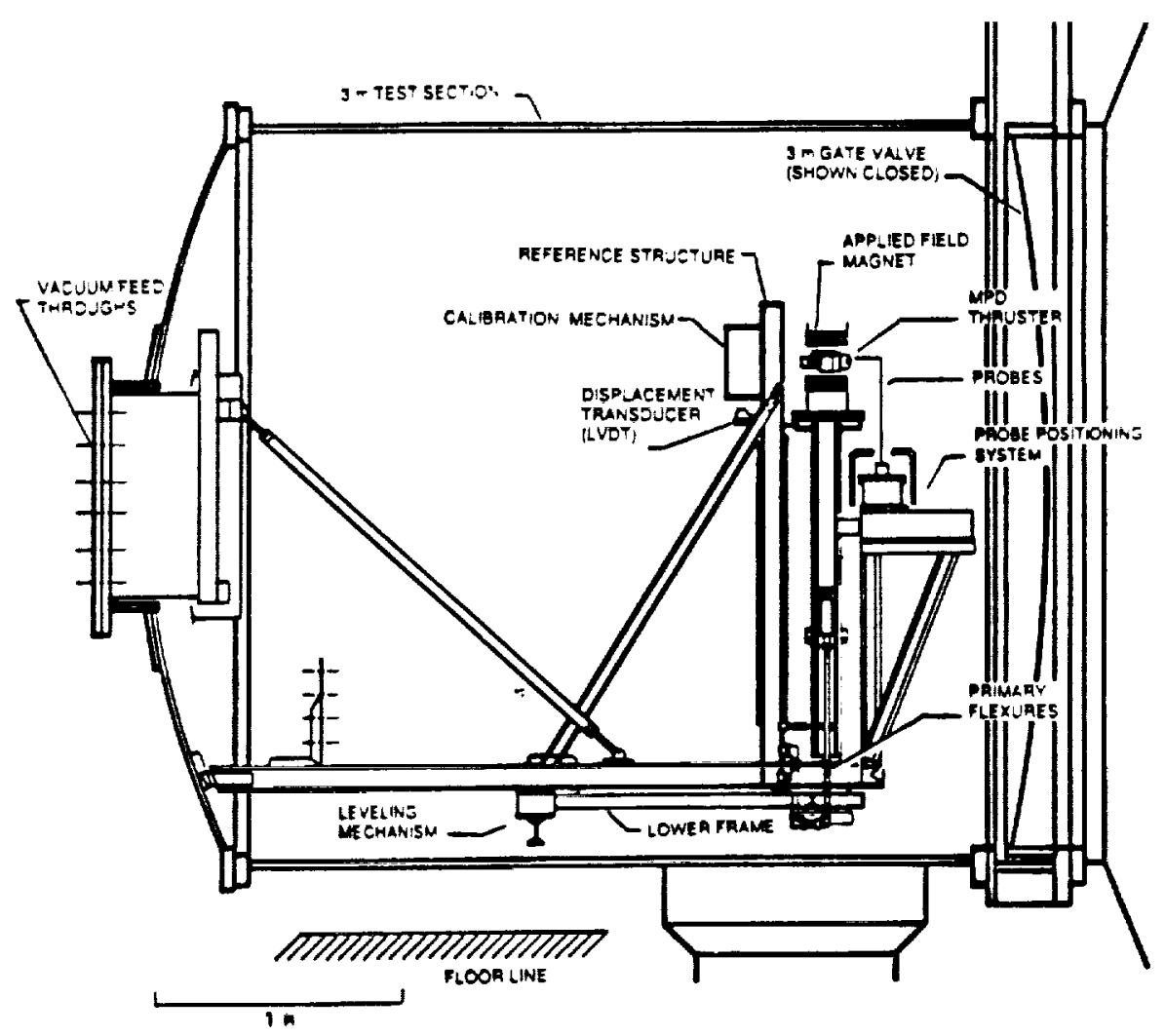

Figure 2. Schematic of MPD thruster test facility showing thrust stand and probe positioning system. 


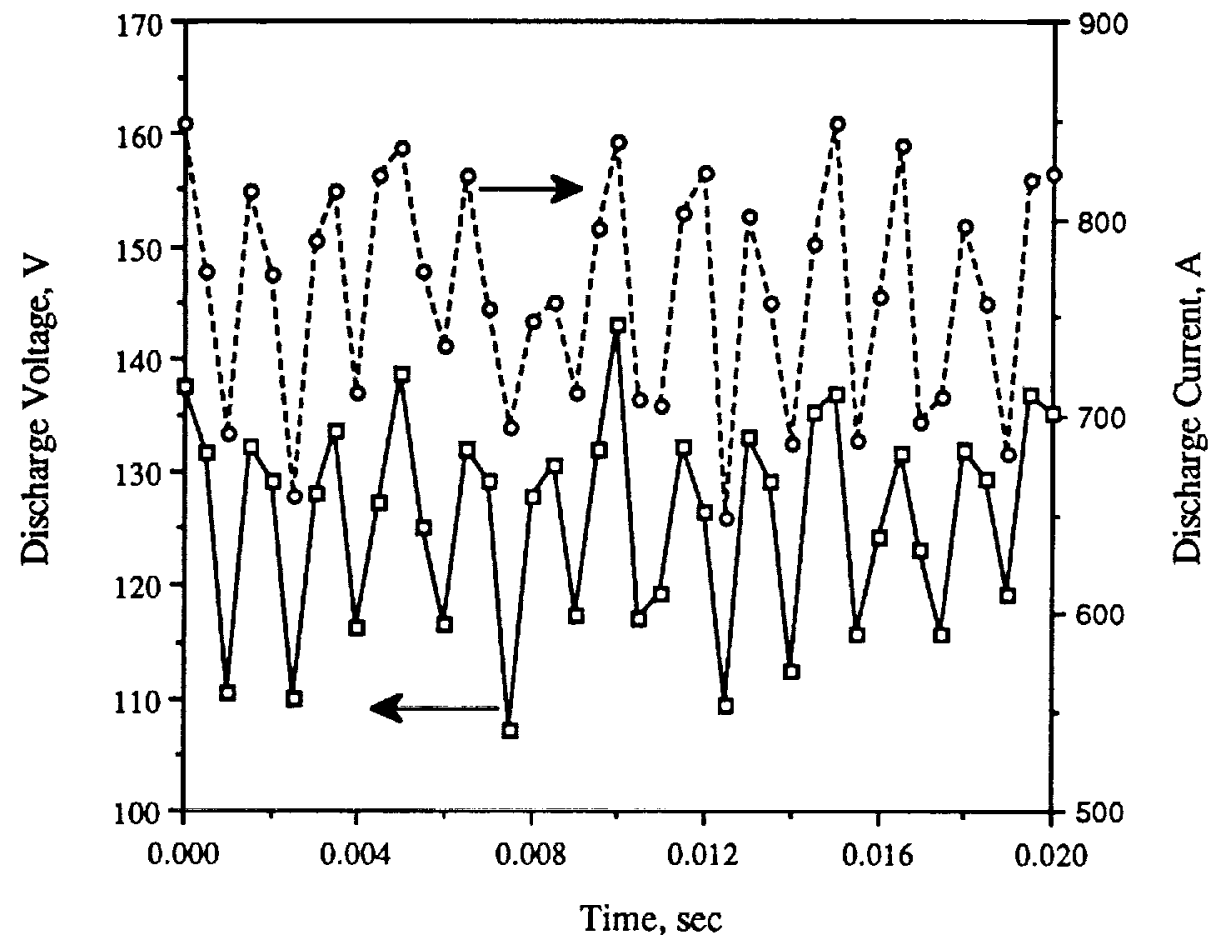

Figure 3. Discharge current and voltage ripples for thruster geometry G. $\mathrm{J}_{\mathrm{d}}=750 \mathrm{~A}, \mathrm{~B}_{\mathrm{z}}=0.182 \mathrm{~T}, 0.1 \mathrm{~g} / \mathrm{s}$ argon.

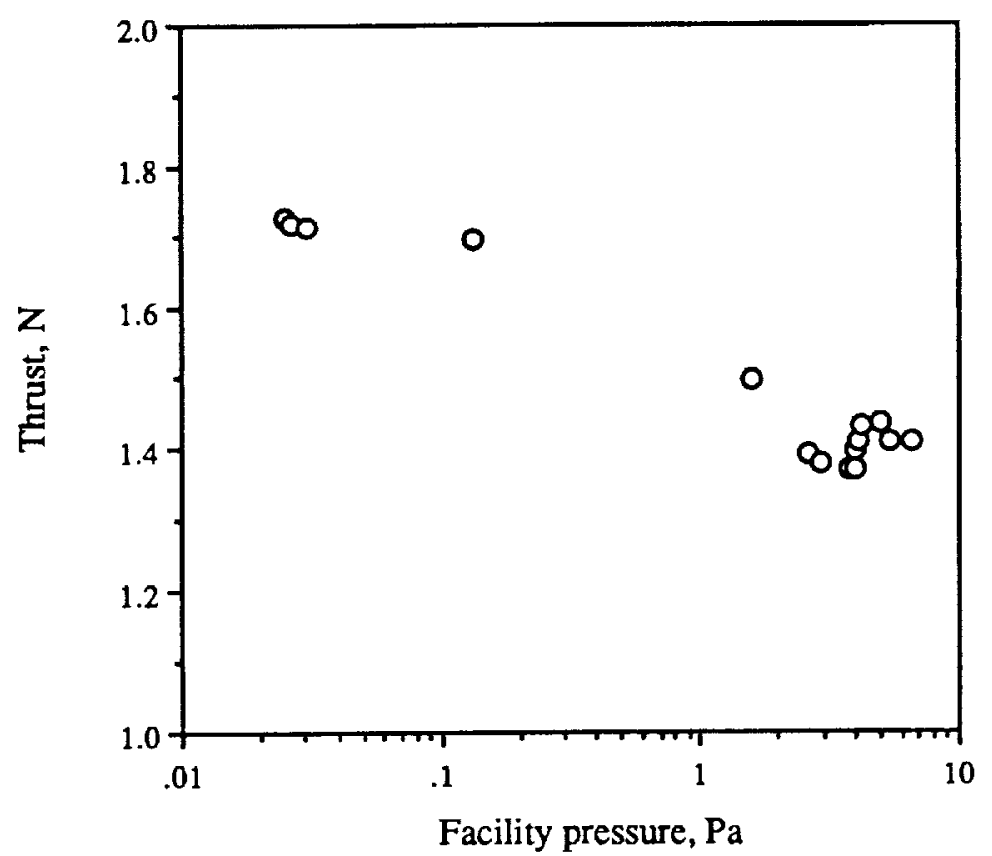

Figure 4. Effect of facility background pressure on thrust. Geometry $\mathrm{C}, \mathrm{J}_{\mathrm{d}}=1500 \mathrm{~A}, \mathrm{~B}_{\mathrm{z}}=0.02 \mathrm{~T}, 0.1 \mathrm{~g} / \mathrm{s}$ argon. 


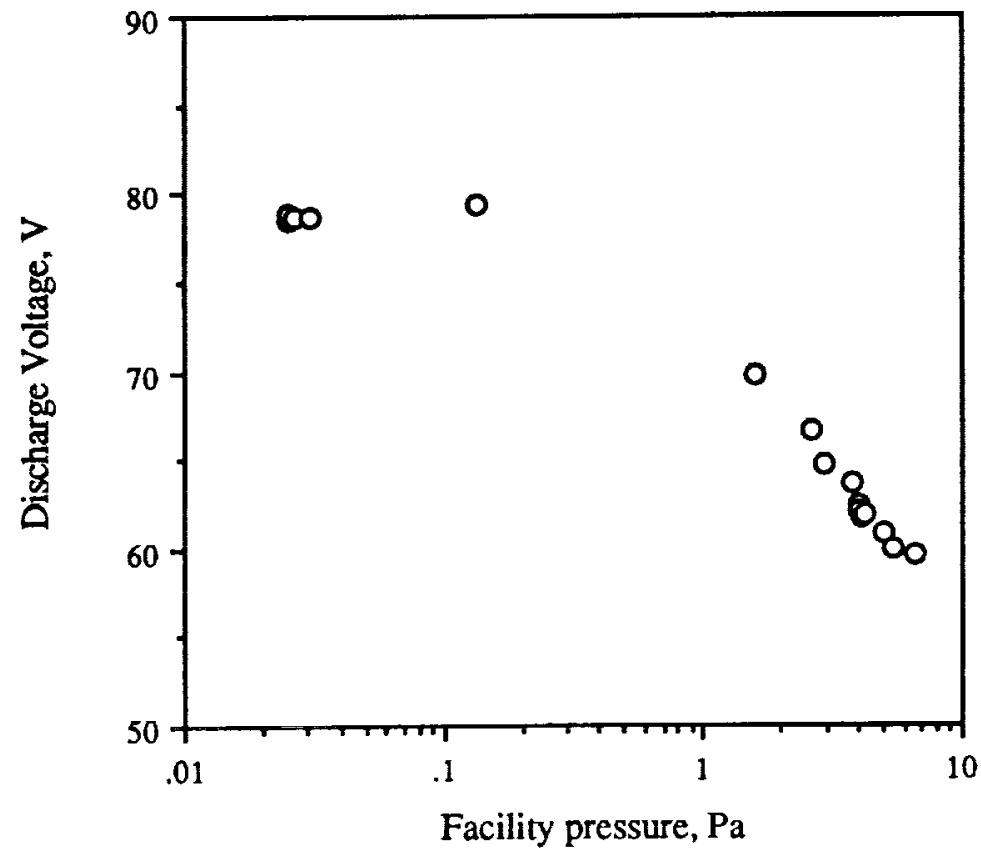

Figure 5. Effect of facility background pressure on the discharge voltage. Geometry $C, J_{d}=1500 \mathrm{~A}, B_{z}=0.02 \mathrm{~T}, 0.1 \mathrm{~g} / \mathrm{s}$ argon.

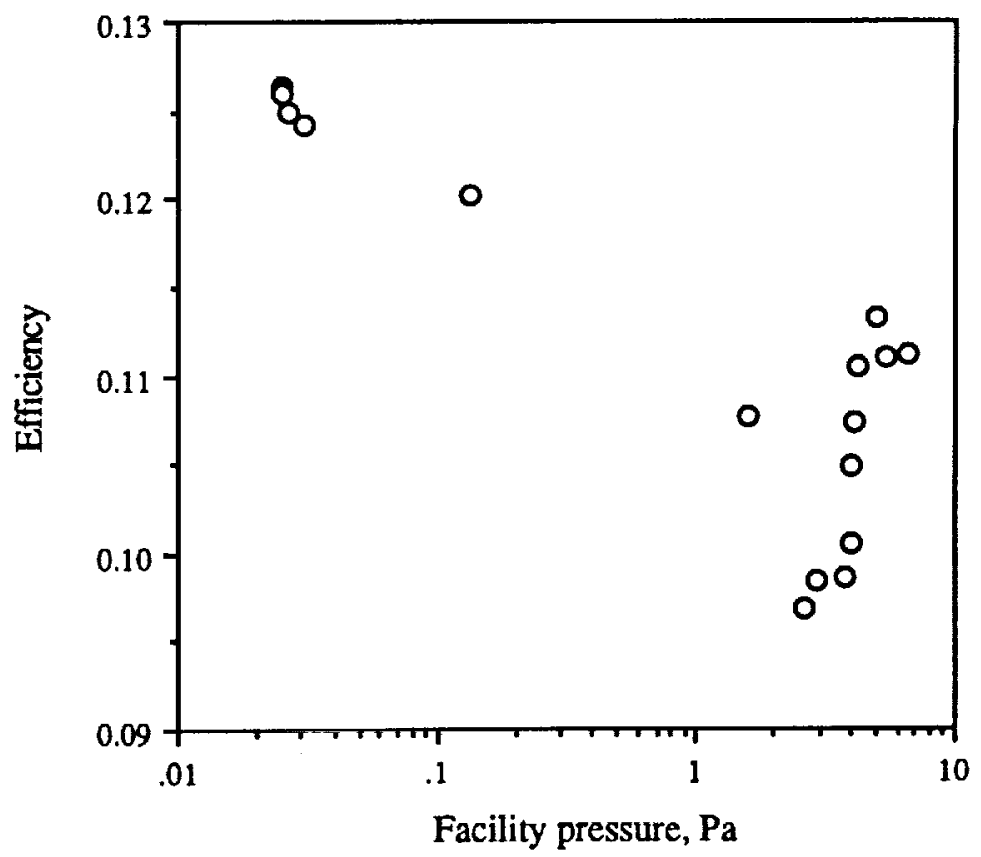

Figure 6. Effect of facility background pressure on efficiency. Geometry $C, J_{d}=1500 \mathrm{~A}, B_{z}=0.02 \mathrm{~T}$. $0.1 \mathrm{~g} / \mathrm{s}$ argon. 


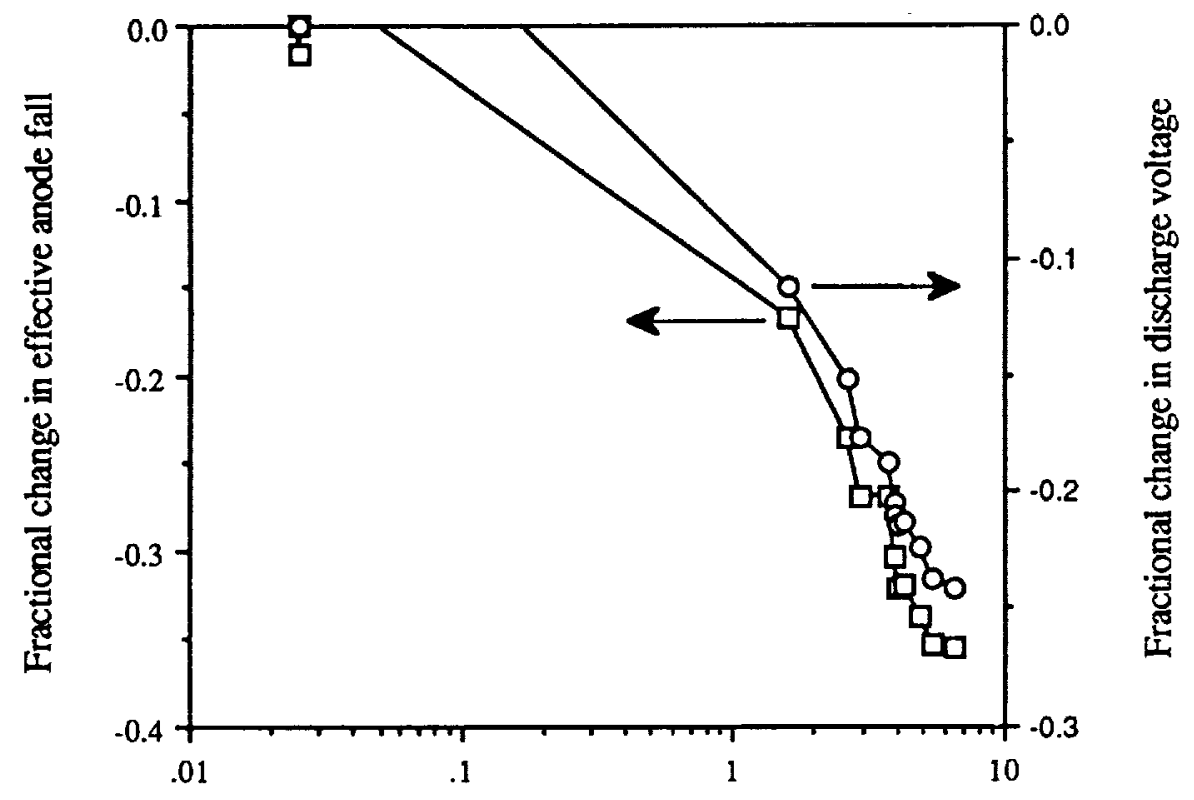

Facility pressure, $\mathrm{Pa}$

Figure 7. Effect of facility pressure on the effective anode fall and discharge voltages. Geometry $\mathrm{C}, \mathrm{J}_{\mathrm{d}}=1500 \mathrm{~A}, \mathrm{~B}_{\mathrm{z}}=0.02 \mathrm{~T}, 0.1 \mathrm{~g} / \mathrm{s}$ argon.

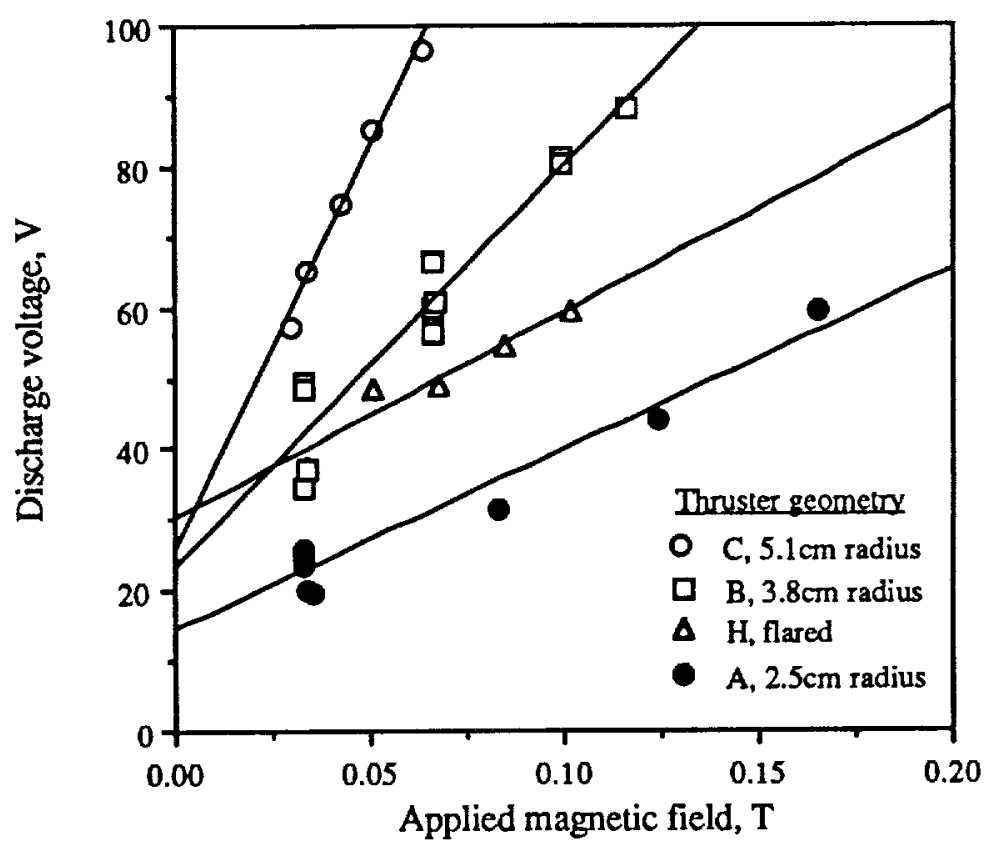

Figure 8. Influence of anode radius on discharge voltage. $\mathrm{L}_{\mathrm{a}}=7.6 \mathrm{~cm}, \mathrm{~J}_{\mathrm{d}}=1000 \mathrm{~A}, 0.1 \mathrm{~g} / \mathrm{s}$ argon. 


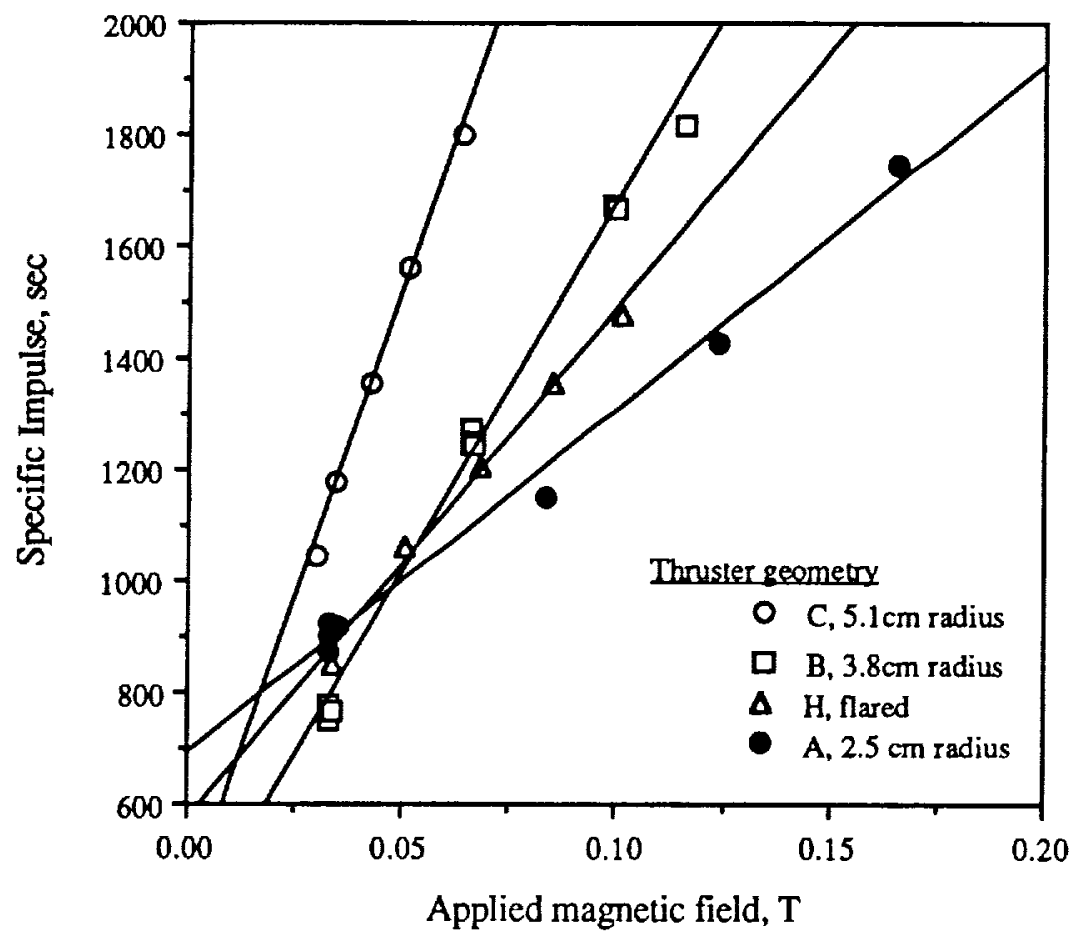

Figure 9. Effect of anode radius on the specific impulse. $\mathrm{L}_{\mathrm{a}}=7.6 \mathrm{~cm}, \mathrm{~J}_{\mathrm{d}}=1000 \mathrm{~A}, 0.1 \mathrm{~g} / \mathrm{s}$ argon.

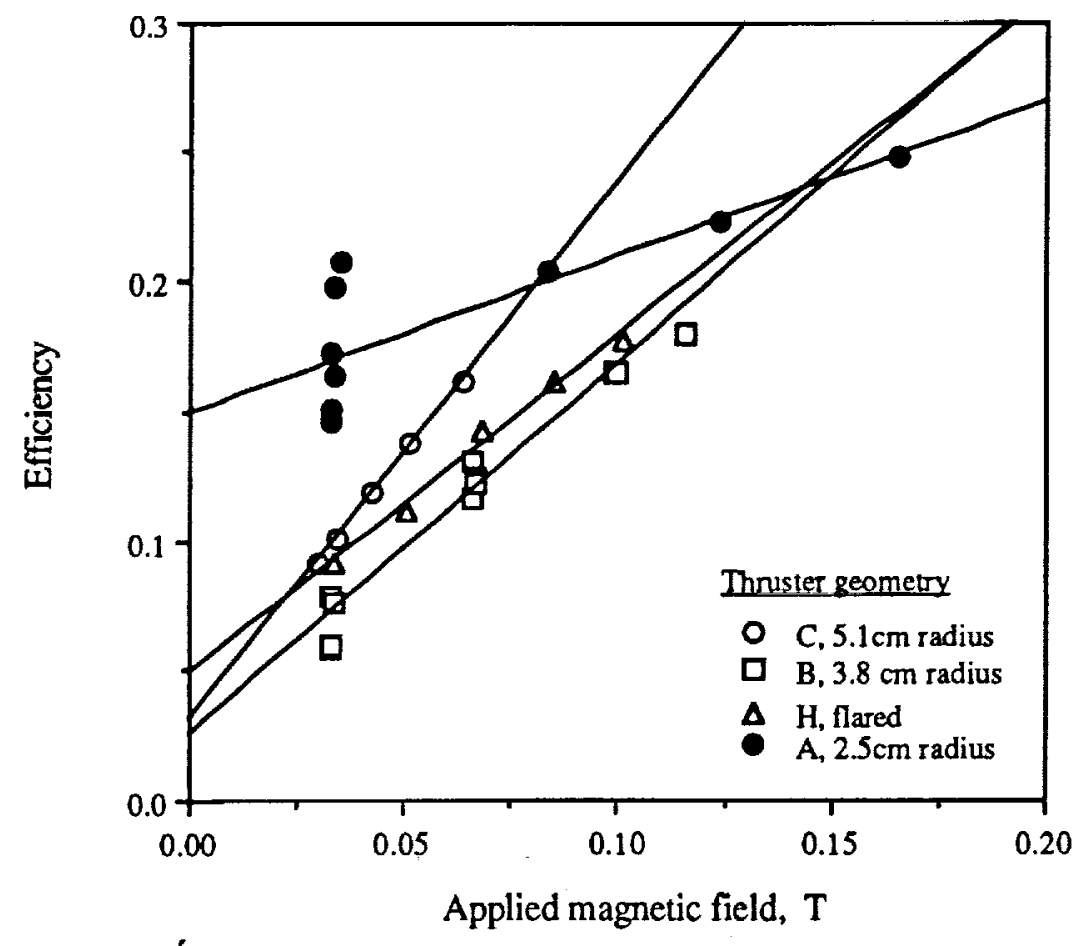

Figure 10. Effect of anode radius on thruster efficiency. $\mathrm{L}_{\mathrm{a}}=7.6 \mathrm{~cm}, \mathrm{~J}_{\mathrm{d}}=1000 \mathrm{~A}, 0.1 \mathrm{~g} / \mathrm{s}$ argon. 


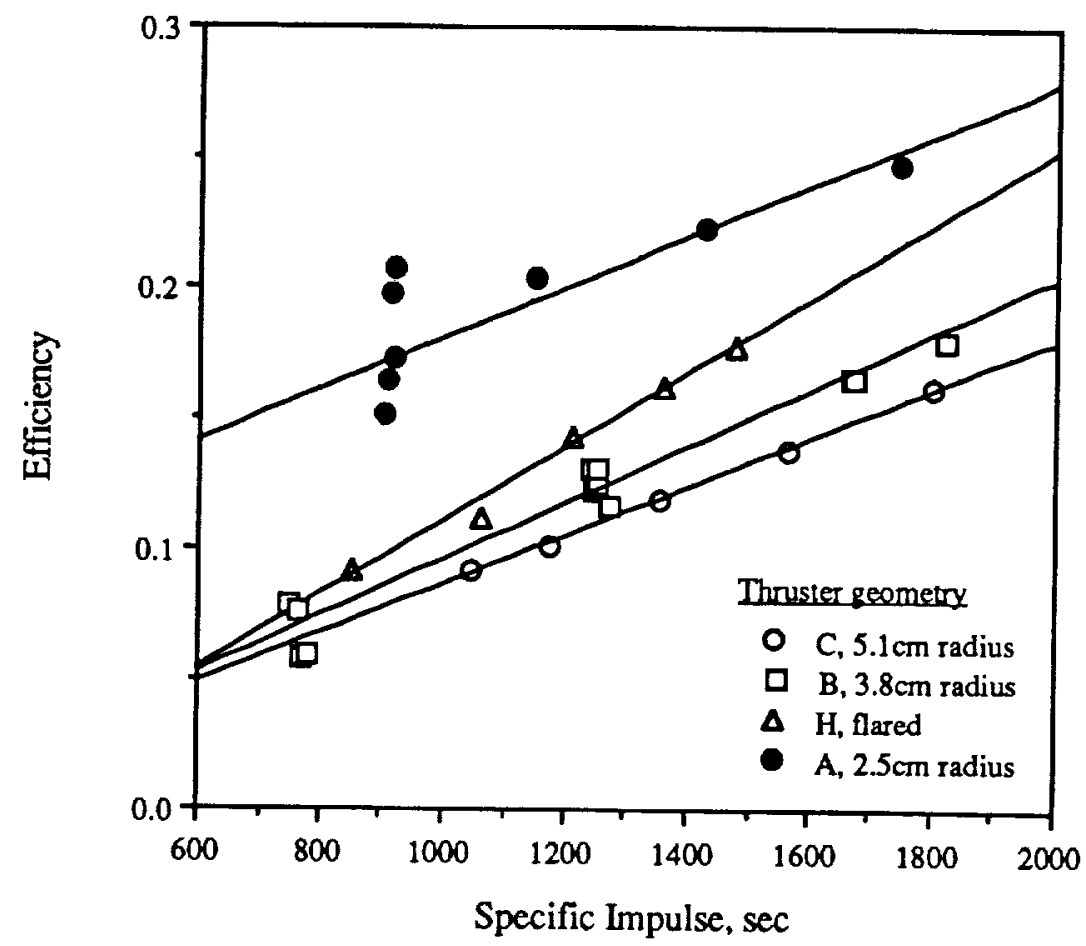

Figure 11. Efficiency vs. specific impulse for four anode radii. $L_{a}=7.6 \mathrm{~cm}, J_{d}=1000 \mathrm{~A}, 0.1 \mathrm{~g} / \mathrm{s}$ argon.

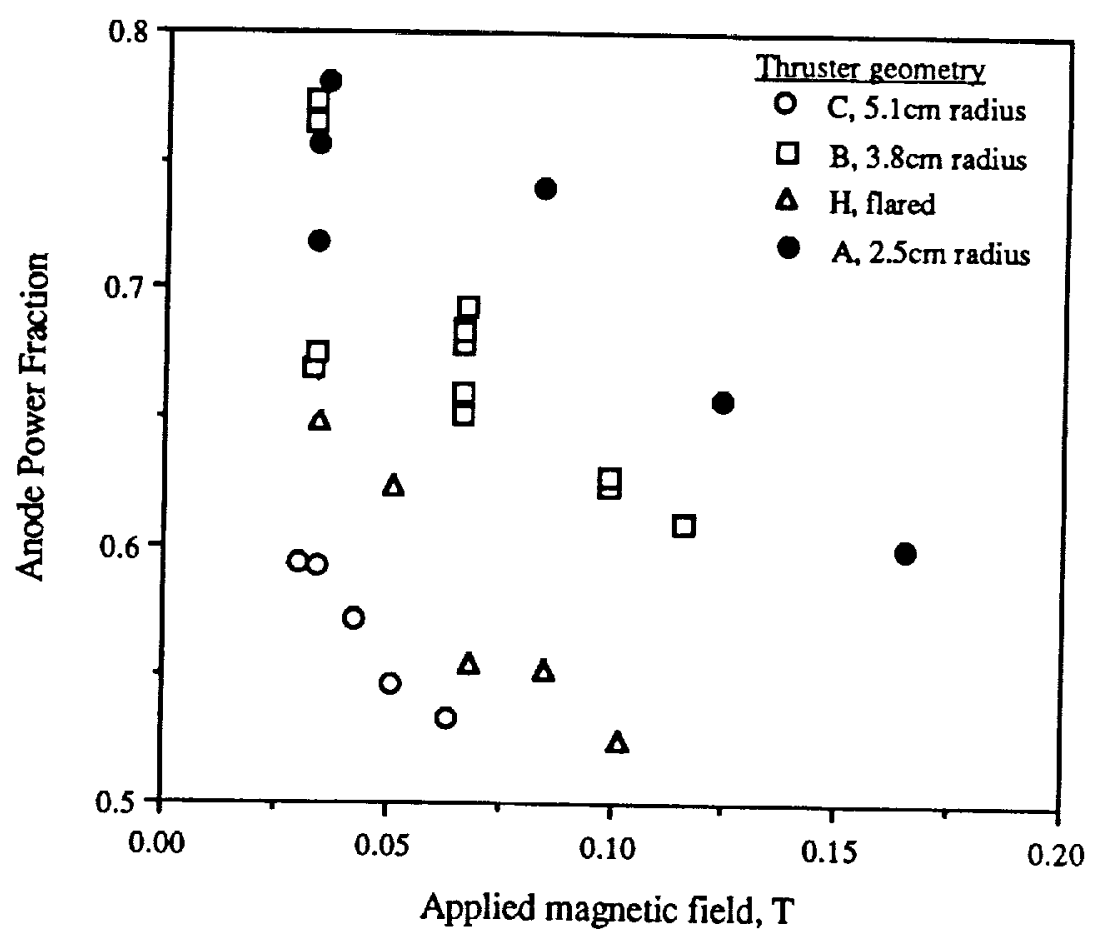

Figure 12. Effect of anode radius on anode power fraction for four anode radii. $\mathrm{L}_{\mathrm{a}}=7.6 \mathrm{~cm}, \mathrm{~J}_{\mathrm{d}}=1000 \mathrm{~A}, 0.1 \mathrm{~g} / \mathrm{s}$ argon. 


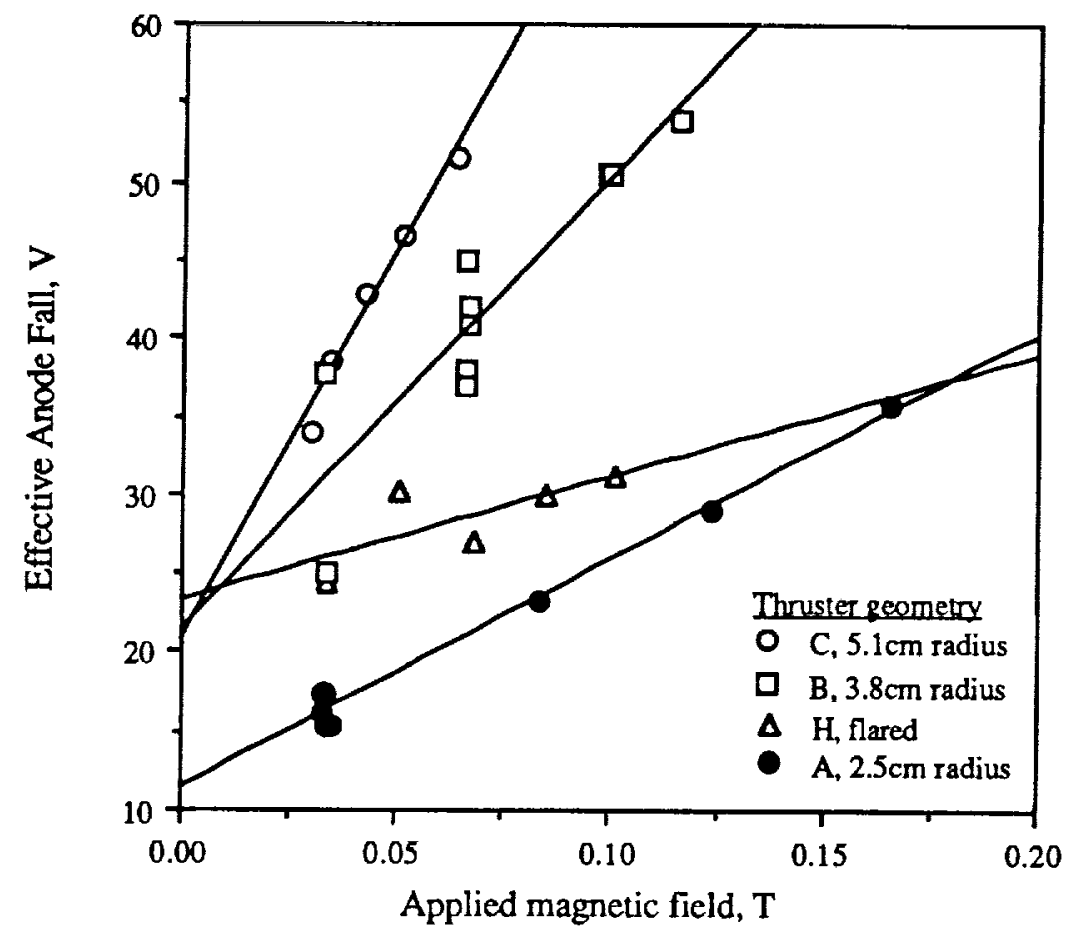

Figure 13. Effect of anode radius on the effective anode fall voltage. $\mathrm{L}_{\mathrm{a}}=7.6 \mathrm{~cm}, \mathrm{~J}_{\mathrm{d}}=1000 \mathrm{~A}, 0.1 \mathrm{~g} / \mathrm{s}$ argon.

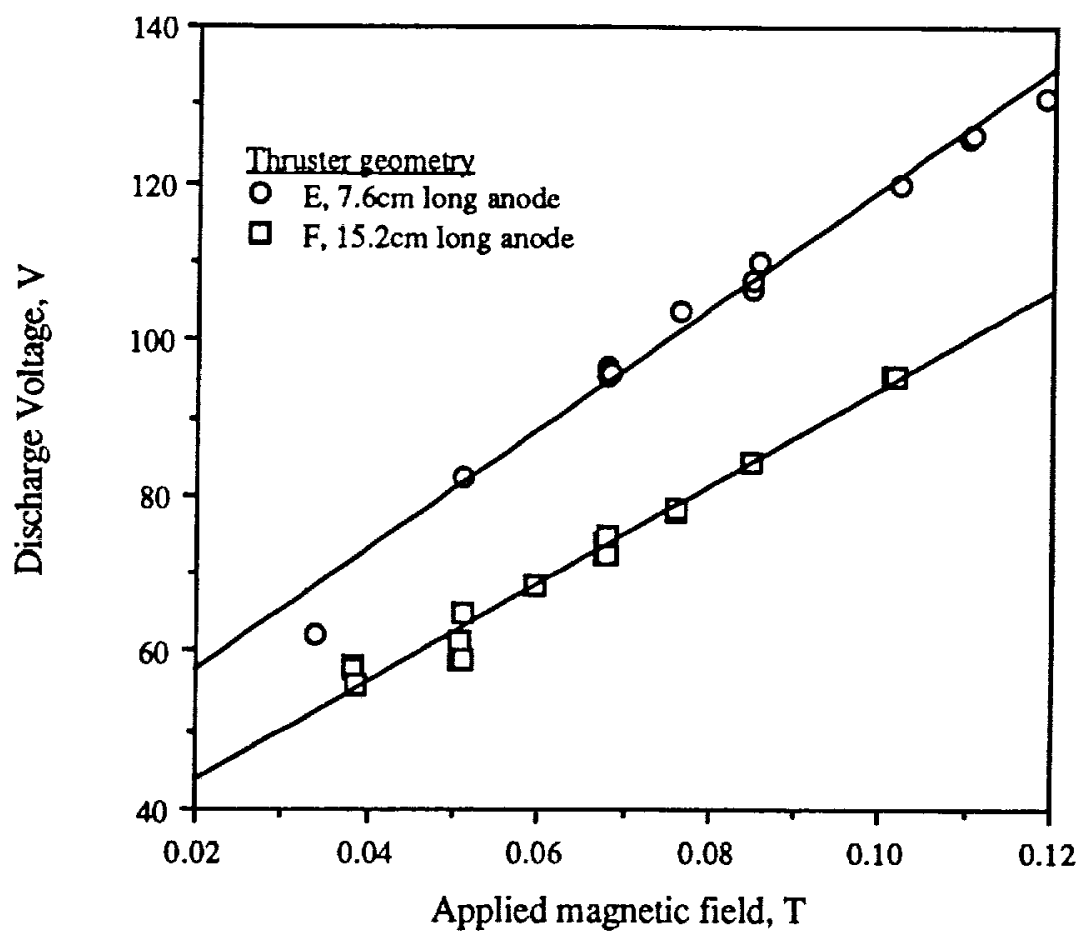

Figure 14. Influence of anode length on discharge voltage. $R_{\mathrm{a}}=5.1 \mathrm{~cm}, \mathrm{~J}_{\mathrm{d}}=1000 \mathrm{~A}, 0.1 \mathrm{~g} / \mathrm{s}$ argon. 


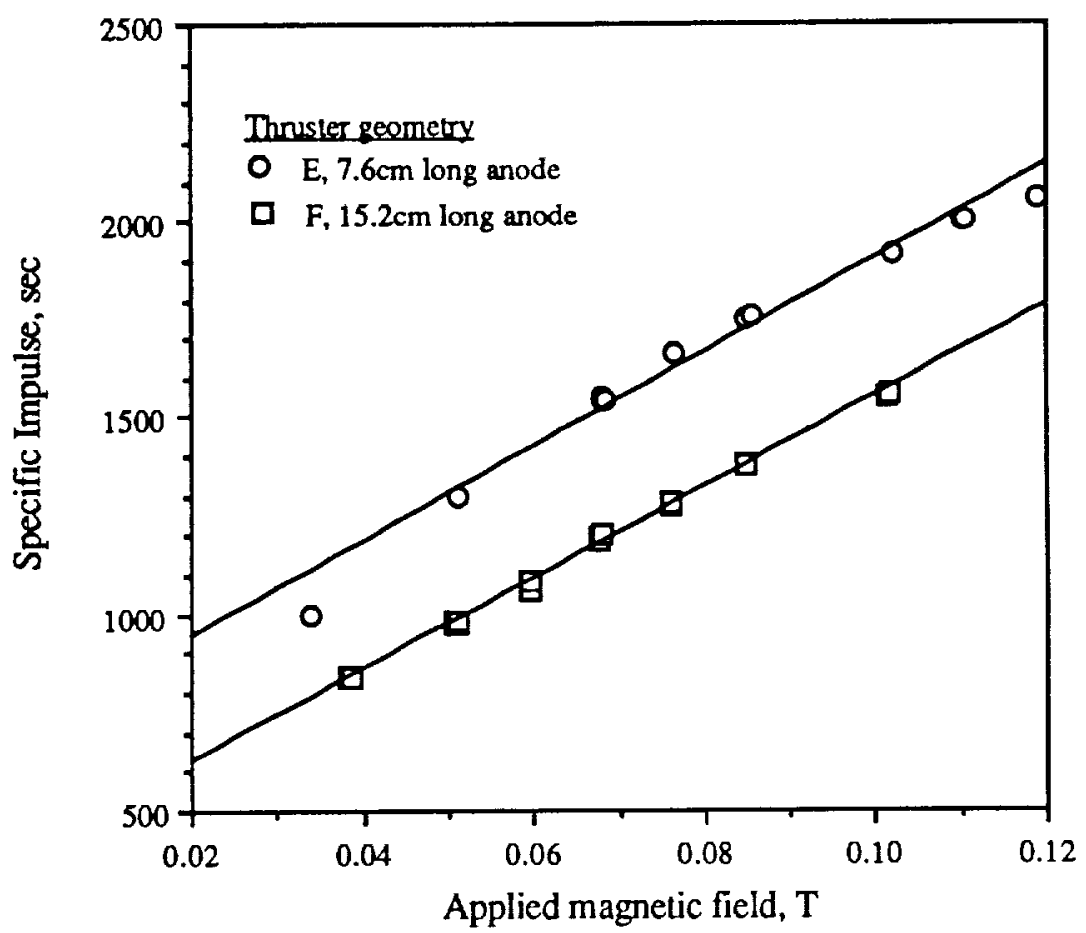

Figure 15. Effect of anode length on the specific impulse. $R_{a}=5.1 \mathrm{~cm}, J_{d}=1000 \mathrm{~A}, 0.1 \mathrm{~g} / \mathrm{s}$ argon.

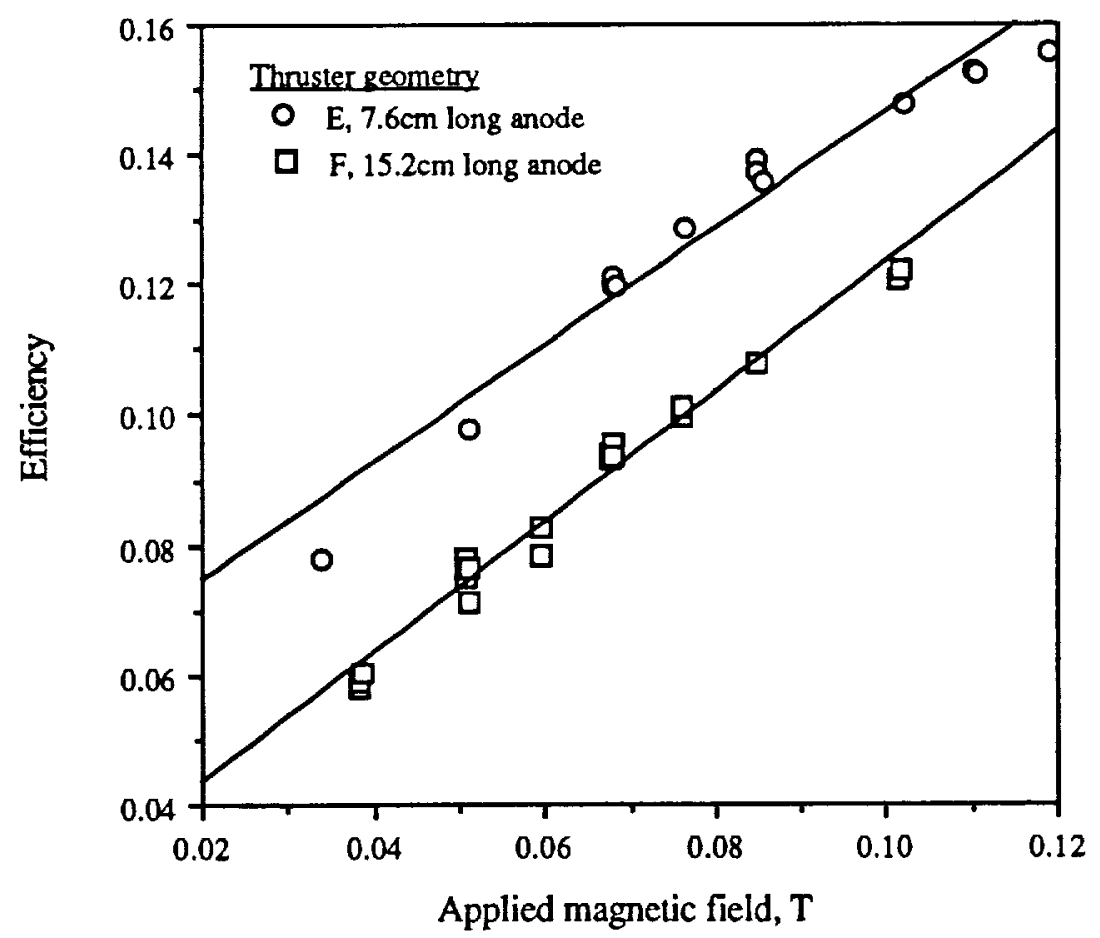

Figure 16. Effect of anode length on thruster efficiency. $R_{a}=5.1 \mathrm{~cm}, J_{d}=1000 \mathrm{~A}, 0.1 \mathrm{~g} / \mathrm{s}$ argon. 


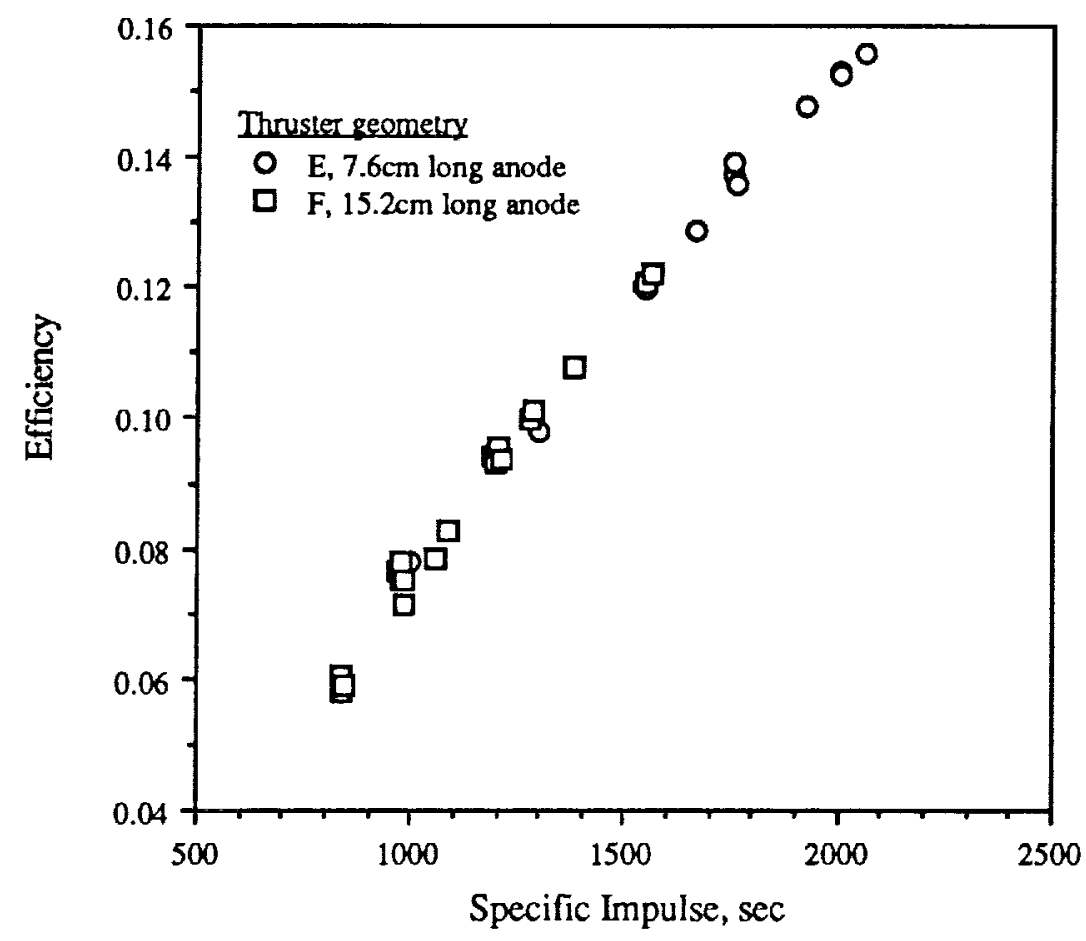

Figure 17. Efficiency vs. specific impulse for two anode lengths. $\mathrm{R}_{\mathrm{a}}=5.1 \mathrm{~cm}, \mathrm{~J}_{\mathrm{d}}=1000 \mathrm{~A}, 0.1 \mathrm{~g} / \mathrm{s}$ argon.

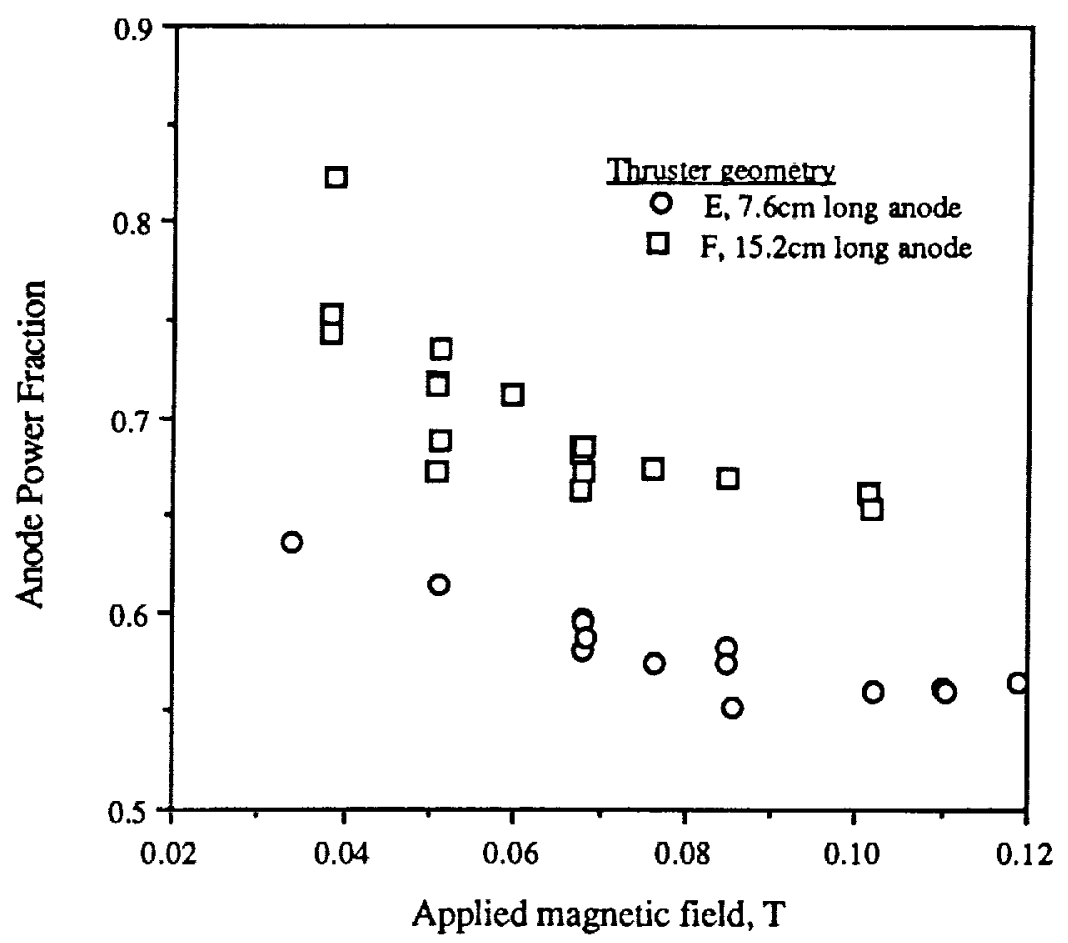

Figure 18. Effect of anode length on anode power fraction. $R_{a}=5.1 \mathrm{~cm}, J_{d}=1000 \mathrm{~A}, 0.1 \mathrm{~g} / \mathrm{s}$ argon. 


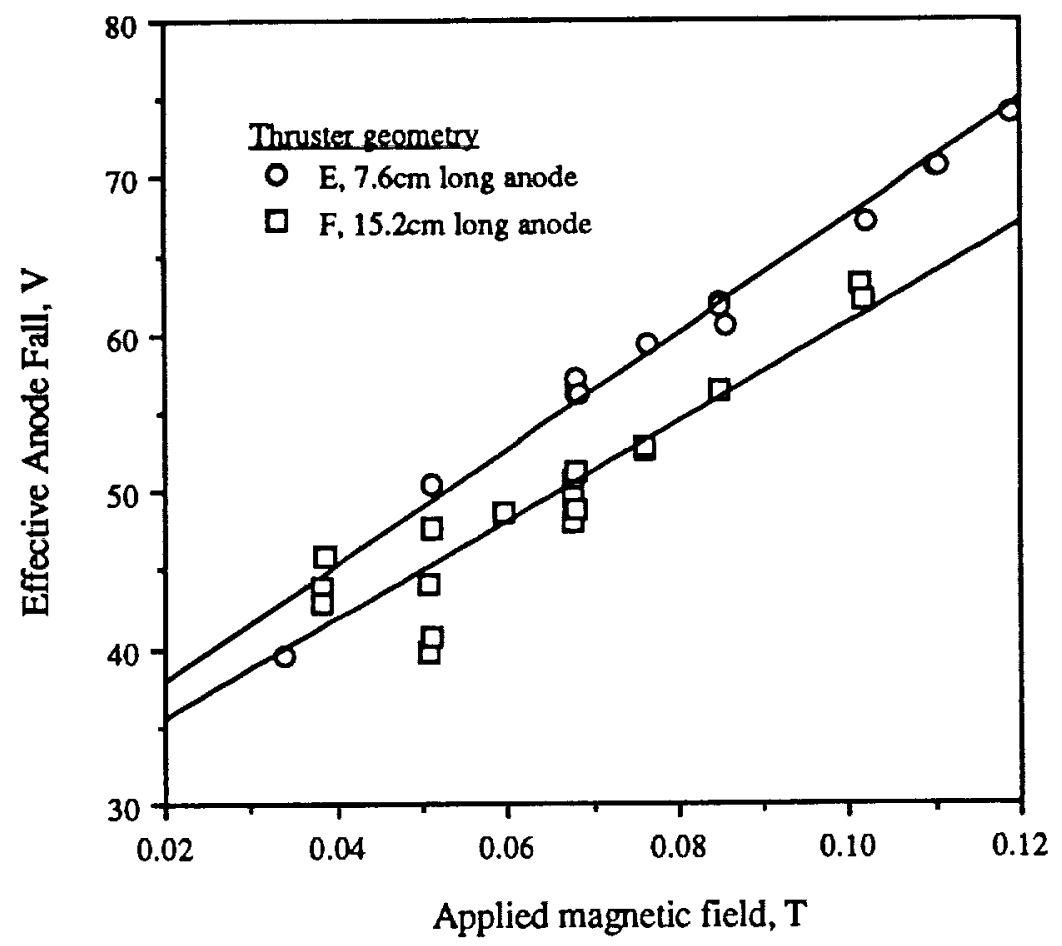

Figure 19. Effect of anode length on the effective anode fall voltage. $R_{\mathrm{a}}=5.1 \mathrm{~cm}, \mathrm{~J}_{\mathrm{d}}=1000 \mathrm{~A}, 0.1 \mathrm{~g} / \mathrm{s}$ argon.

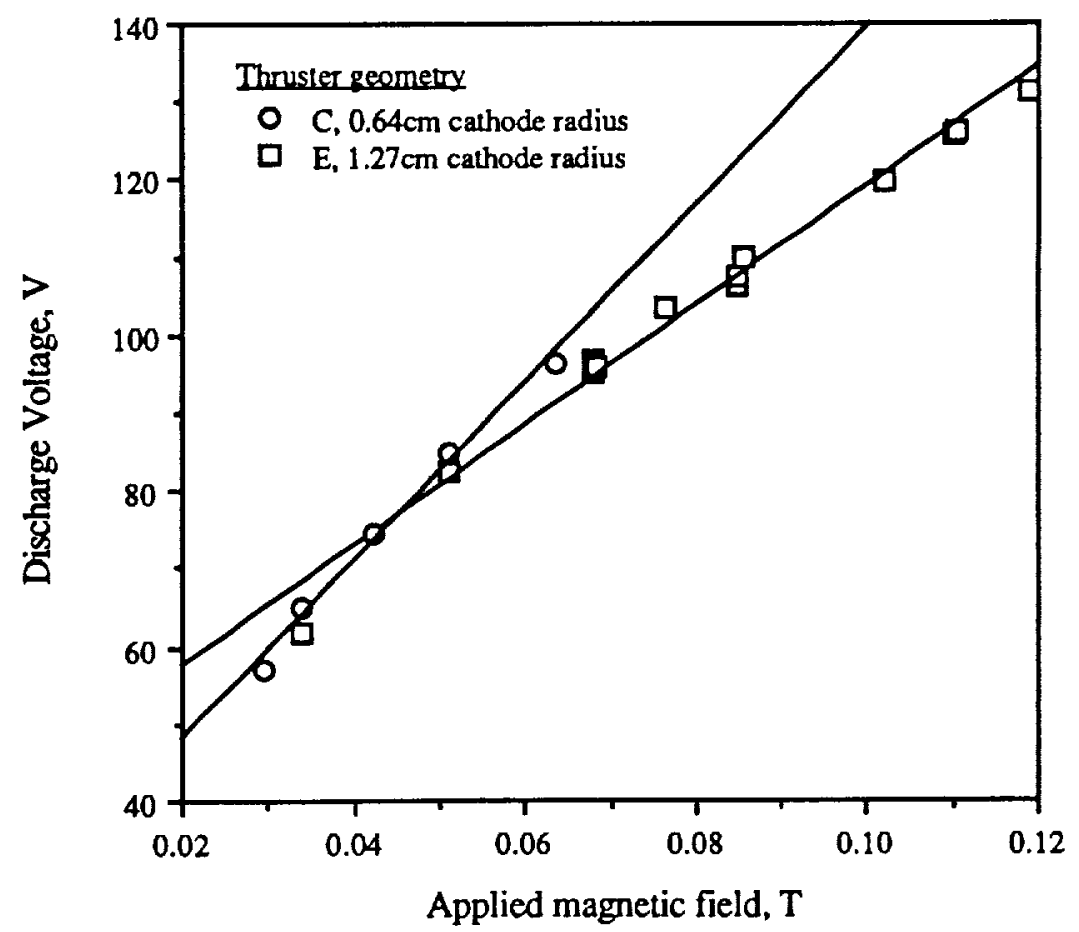

Figure 20. Influence of cathode radius on discharge voltage. $R_{a}=5.1 \mathrm{~cm}, J_{d}=1000 \mathrm{~A}, 0.1 \mathrm{~g} / \mathrm{s}$ argon. 


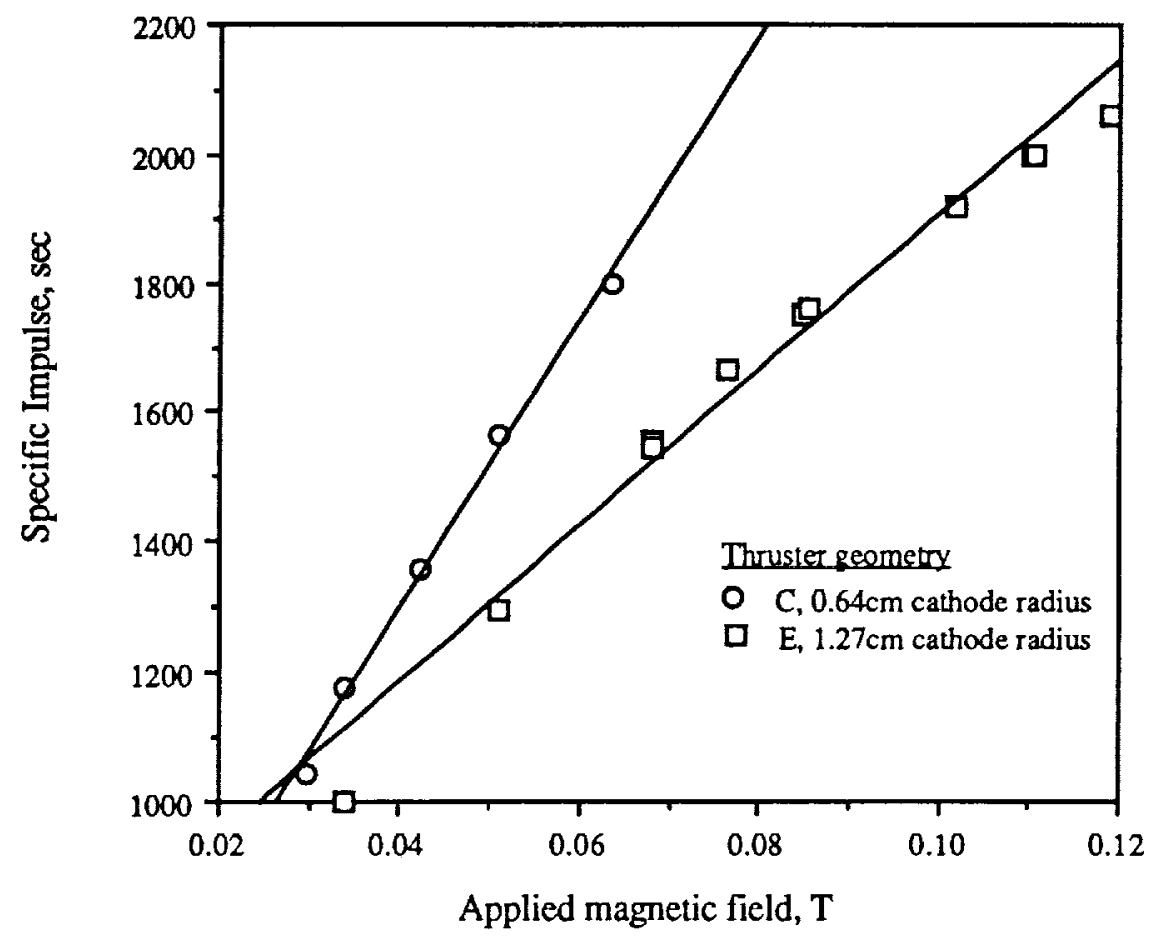

Figure 21. Effect of cathode radius on the specific impulse. $R_{\mathrm{a}}=5.1 \mathrm{~cm}, \mathrm{~J}_{\mathrm{d}}=1000 \mathrm{~A}, 0.1 \mathrm{~g} / \mathrm{s}$ argon.

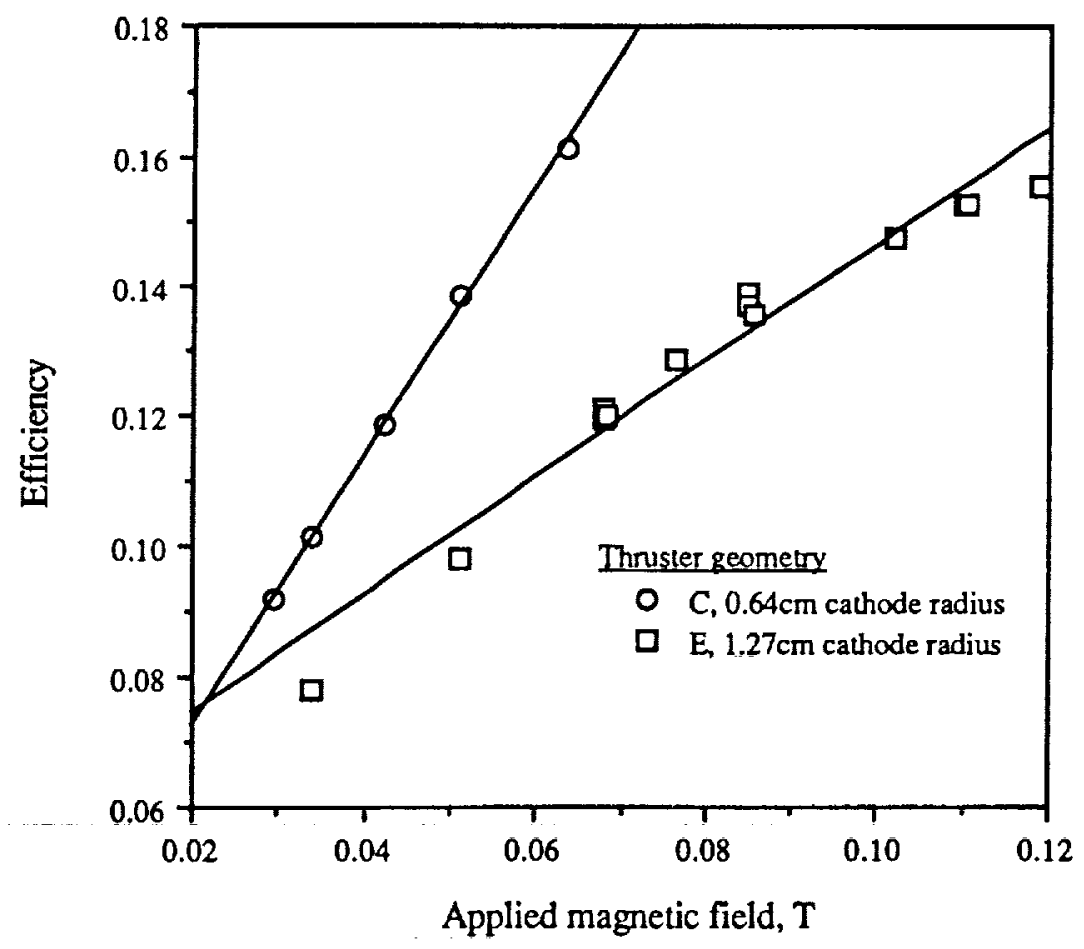

Figure 22. Effect of cathode radius on thruster efficiency. $R_{\mathrm{a}}=5.1 \mathrm{~cm}, \mathrm{~J}_{\mathrm{d}}=1000 \mathrm{~A}, 0.1 \mathrm{~g} / \mathrm{s}$ argon. 


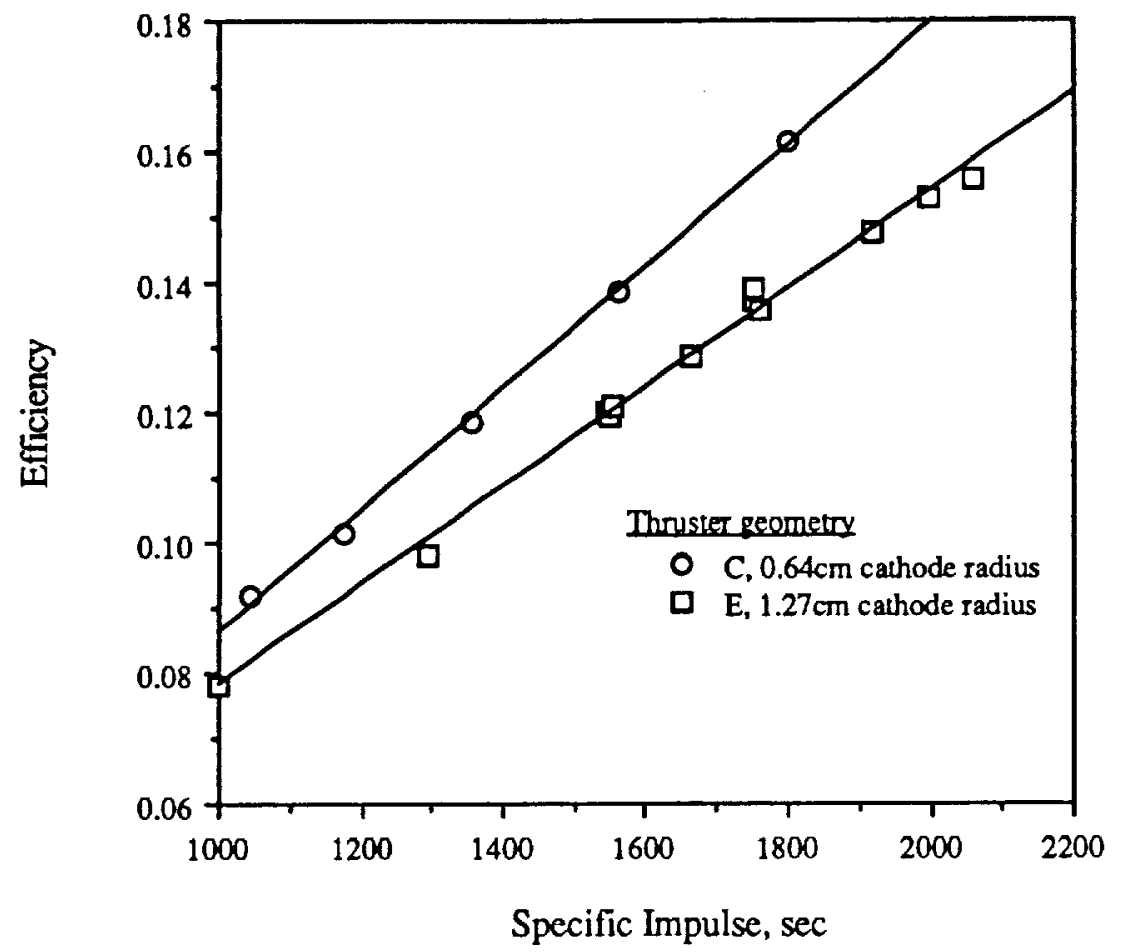

Figure 23. Efficiency vs. specific impulse for two cathode radii. $R_{\mathrm{a}}=5.1 \mathrm{~cm}, \mathrm{~J}_{\mathrm{d}}=1000 \mathrm{~A}, 0.1 \mathrm{~g} / \mathrm{s}$ argon.

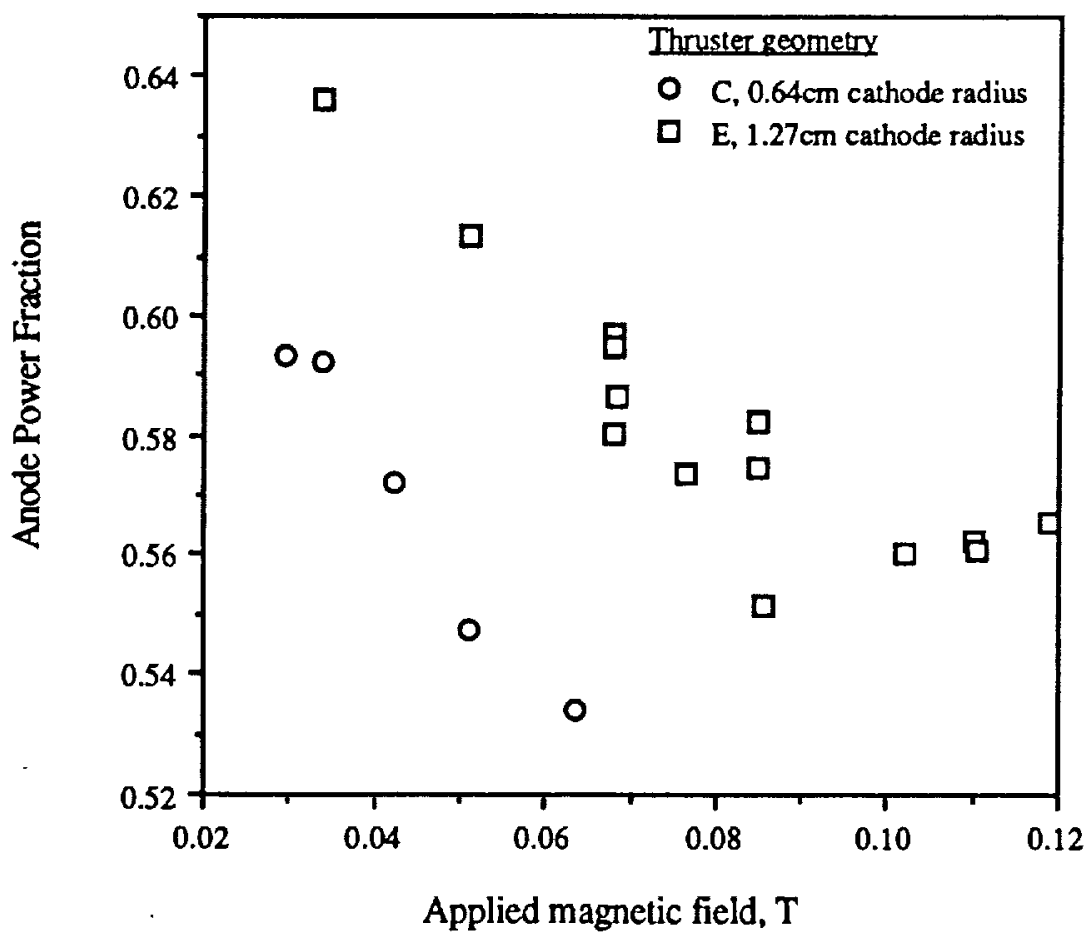

Figure 24. Effect of cathode radius on anode power fraction. $R_{a}=5.1 \mathrm{~cm}, J_{d}=1000 \mathrm{~A}, 0.1 \mathrm{~g} / \mathrm{s}$ argon. 


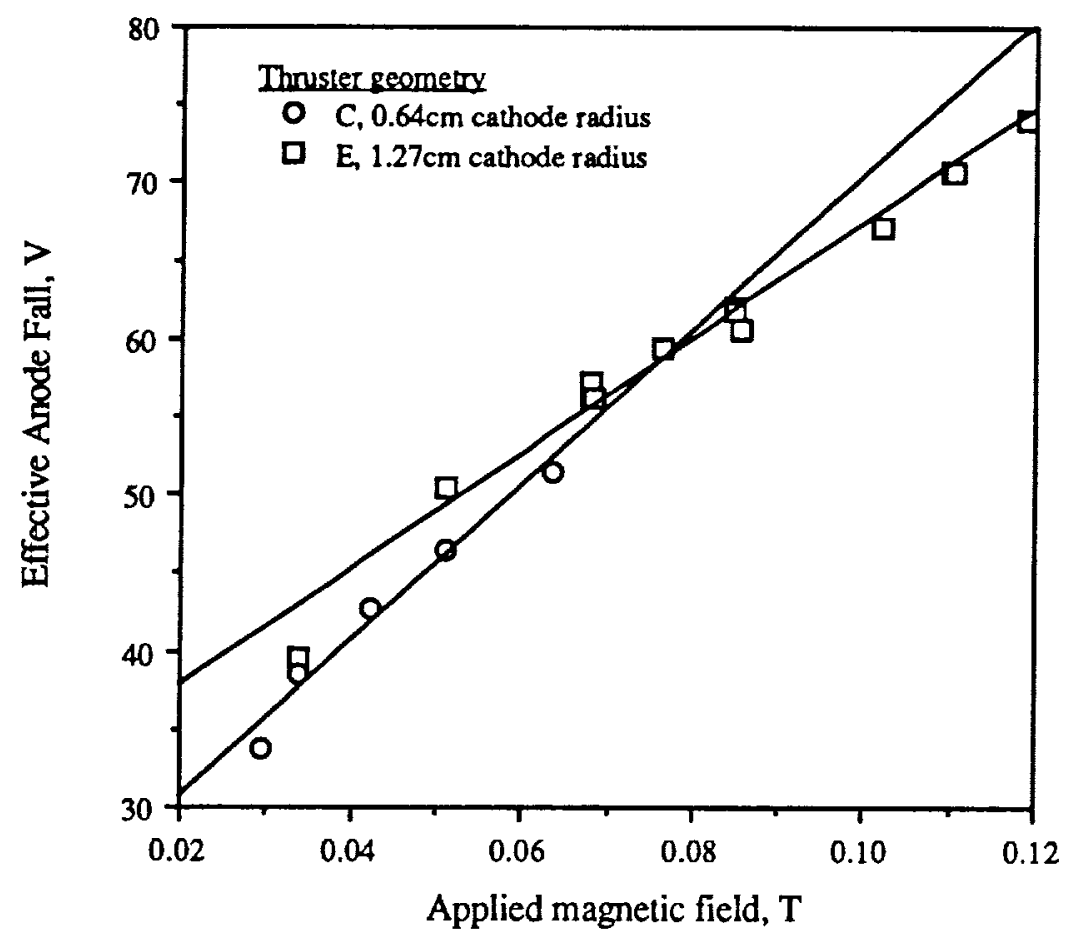

Figure 25. Effect of cathode radius on the effective anode fall voltage. $R_{a}=5.1 \mathrm{~cm}, J_{d}=1000 \mathrm{~A}, 0.1 \mathrm{~g} / \mathrm{s}$ argon.

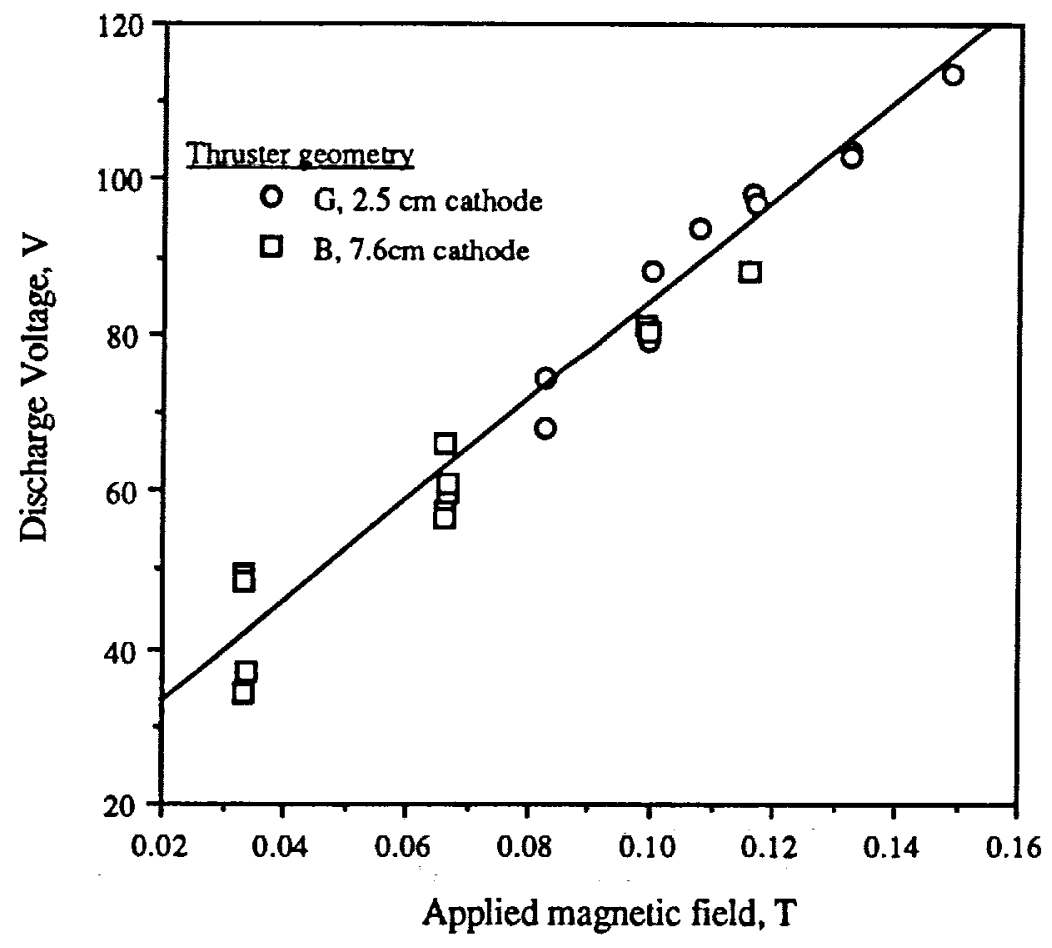

Figure 26. Influence of cathode length on discharge voltage. $\mathrm{R}_{\mathrm{a}}=3.8 \mathrm{~cm}, \mathrm{~J}_{\mathrm{d}}=1000 \mathrm{~A}, 0.1 \mathrm{~g} / \mathrm{s}$ argon. 


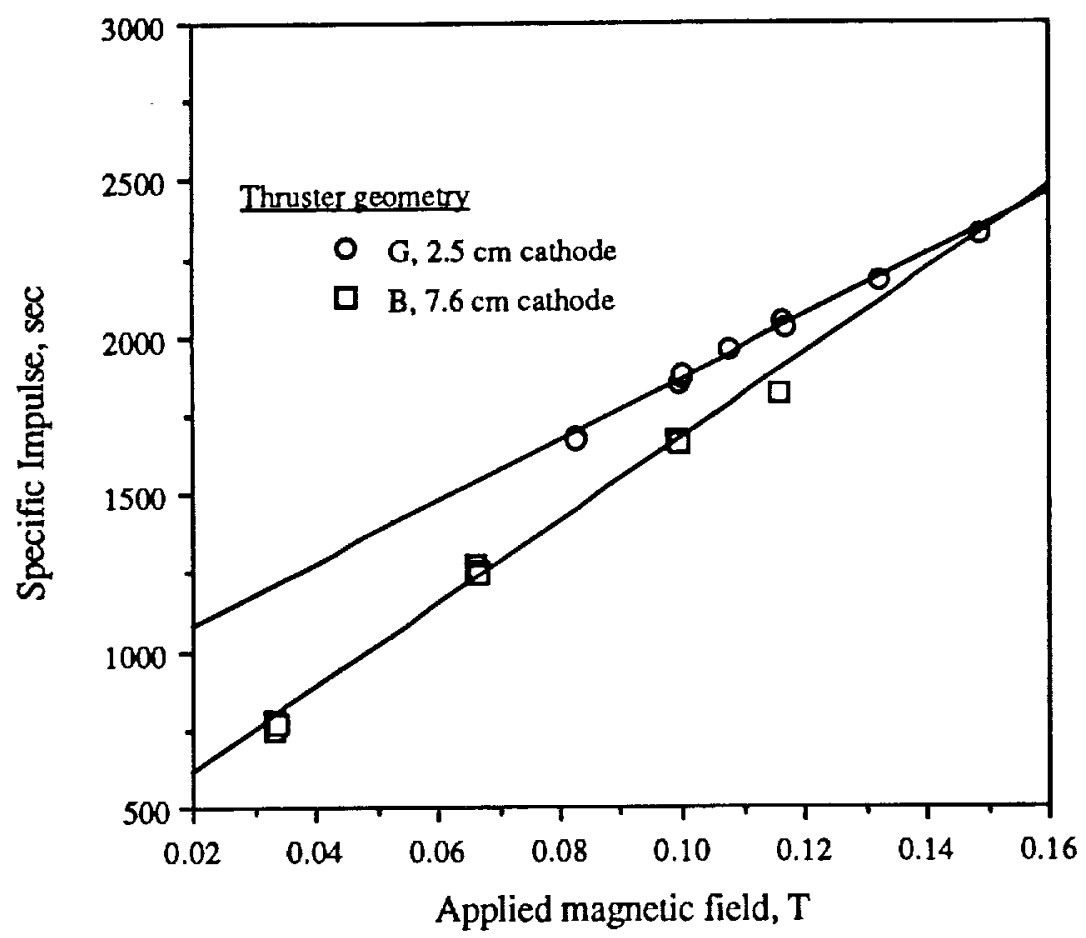

Figure 27. Effect of cathode length on the specific impulse. $R_{a}=3.8 \mathrm{~cm}, J_{d}=1000 \mathrm{~A}, 0.1 \mathrm{~g} / \mathrm{s}$ argon.

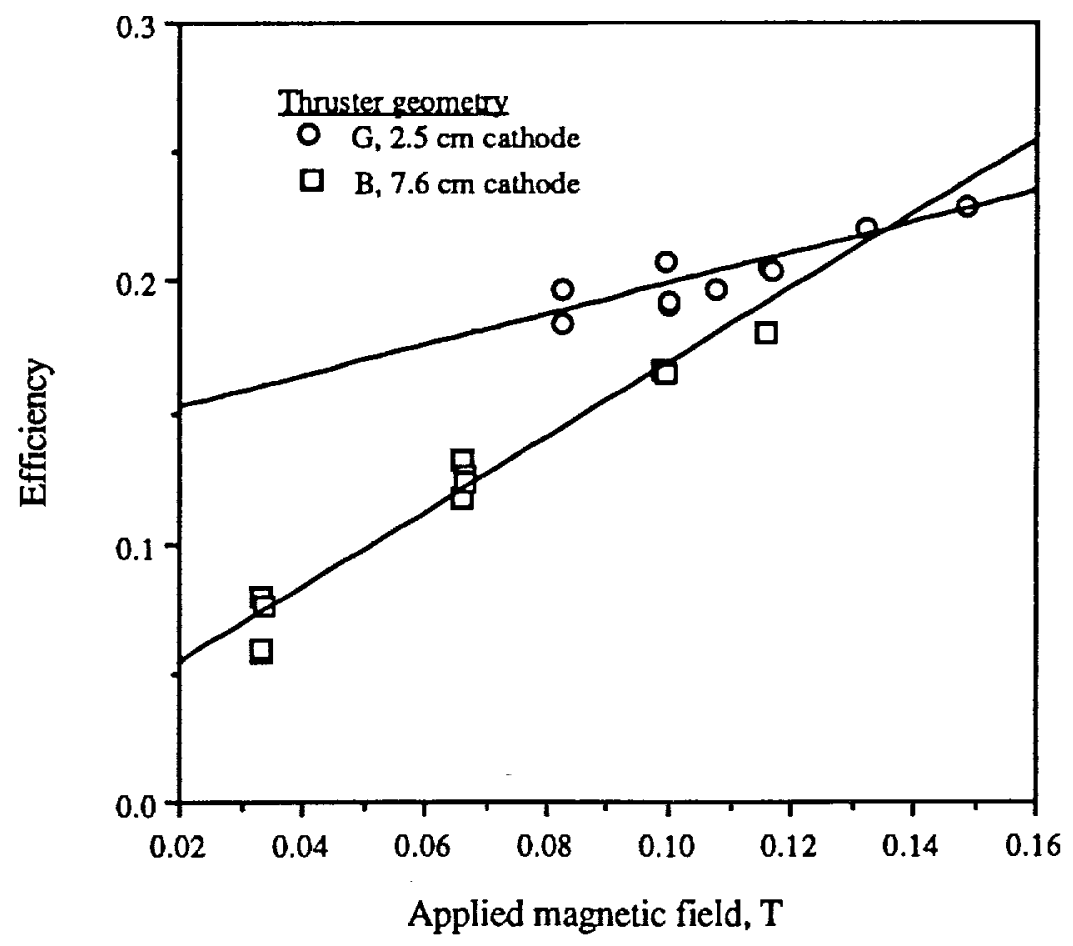

Figure 28. Effect of cathode length on thruster efficiency. $R_{\mathrm{a}}=3.8 \mathrm{~cm}, \mathrm{~J}_{\mathrm{d}}=1000 \mathrm{~A}, 0.1 \mathrm{~g} / \mathrm{s}$ argon. 


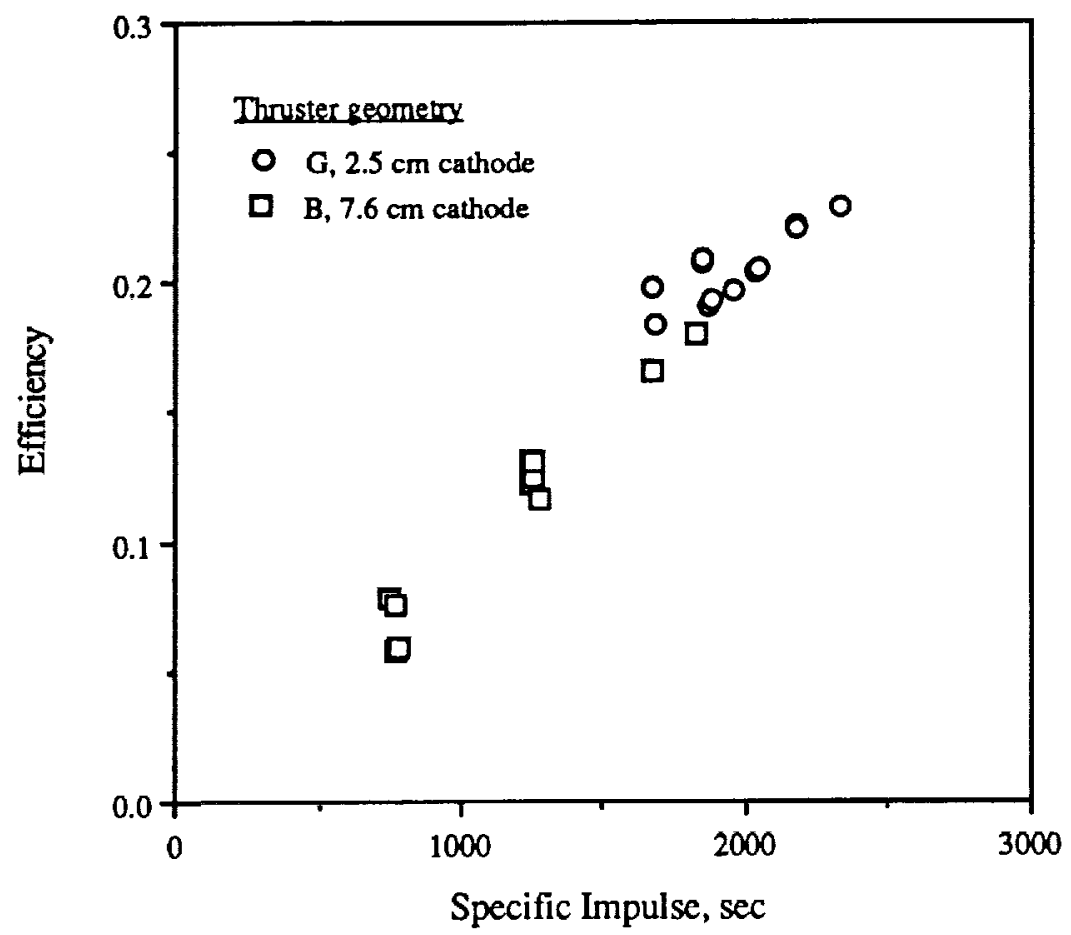

Figure 29. Efficiency vs. specific impulse for two cathode length. $R_{\mathrm{a}}=3.8 \mathrm{~cm}, \mathrm{~J}_{\mathrm{d}}=1000 \mathrm{~A}, 0.1 \mathrm{~g} / \mathrm{s}$ argon.

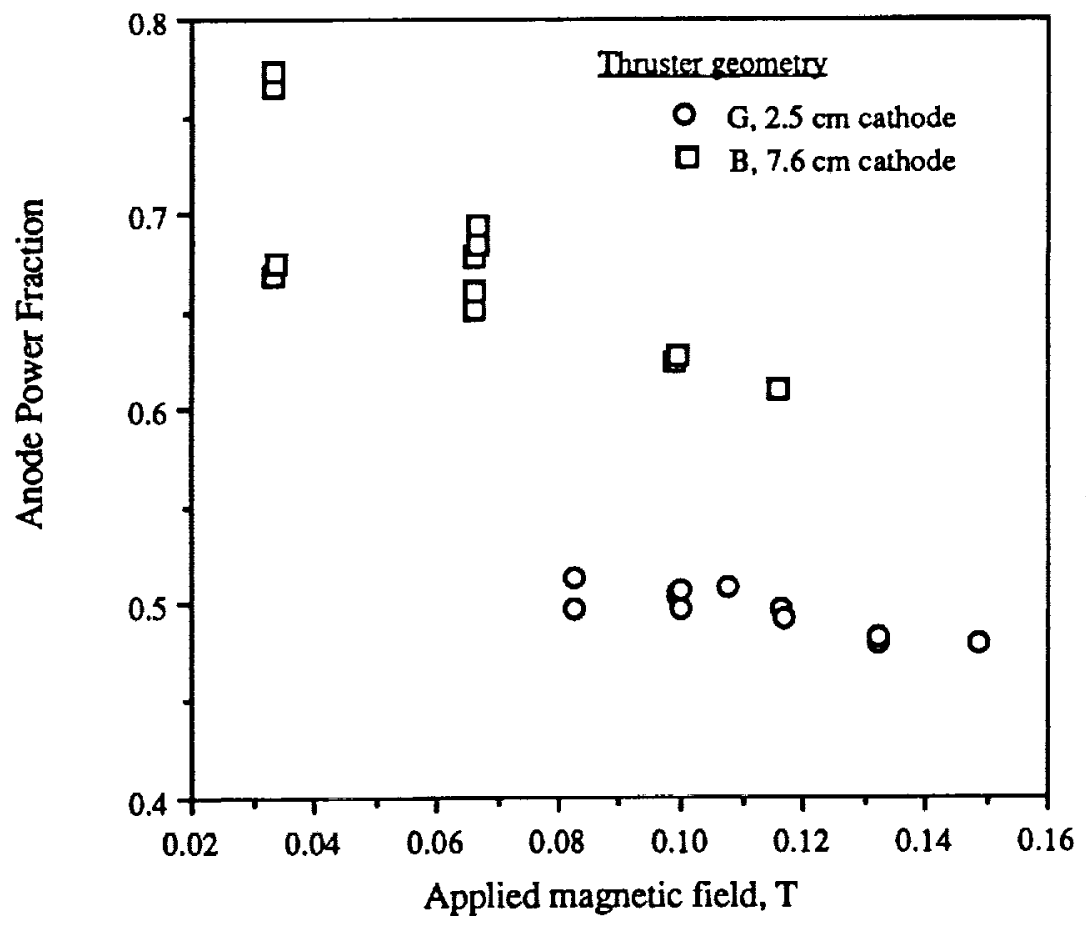

Figure 30. Effect of cathode length on anode power fraction. $R_{a}=3.8 \mathrm{~cm}, J_{d}=1000 \mathrm{~A}, 0.1 \mathrm{~g} / \mathrm{s}$ argon. 


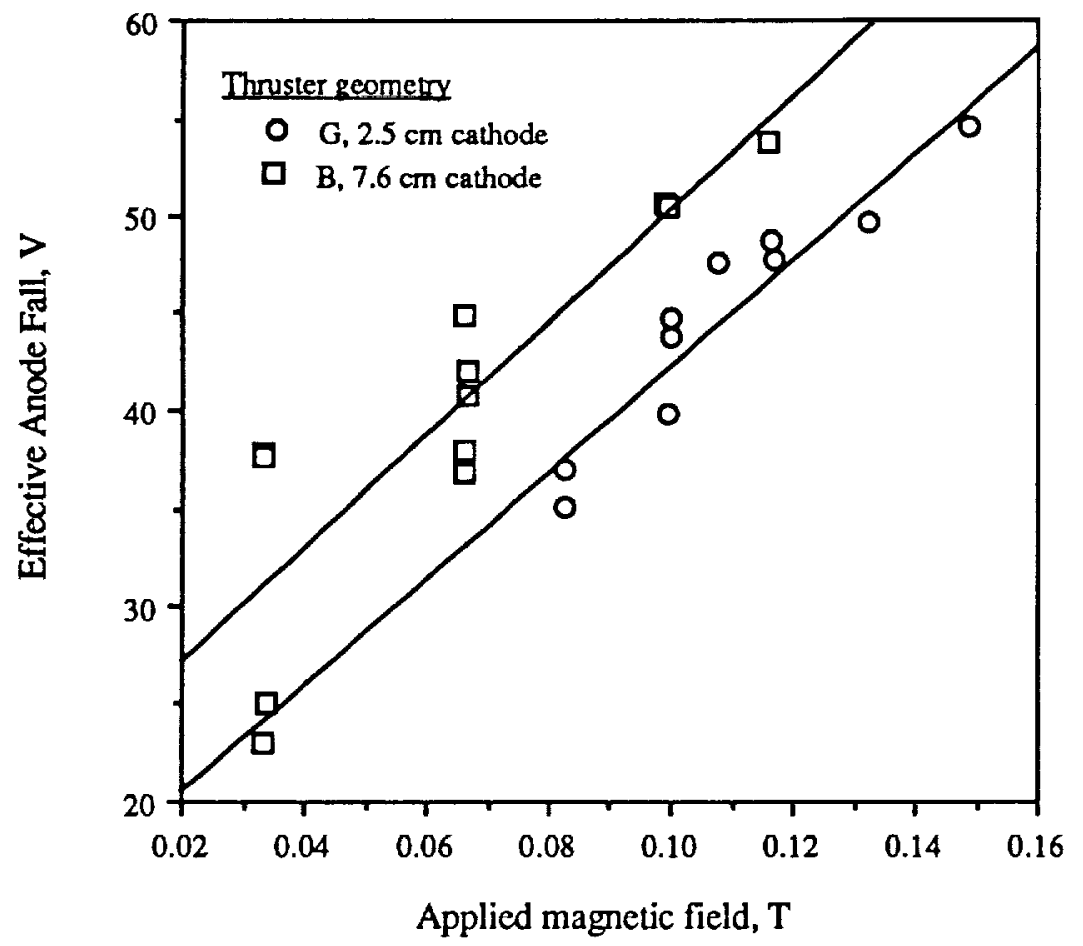

Figure 31. Effect of cathode length on the effective anode fall voltage. $R_{a}=3.8 \mathrm{~cm}, J_{d}=1000 \mathrm{~A}, 0.1 \mathrm{~g} / \mathrm{s}$ argon.

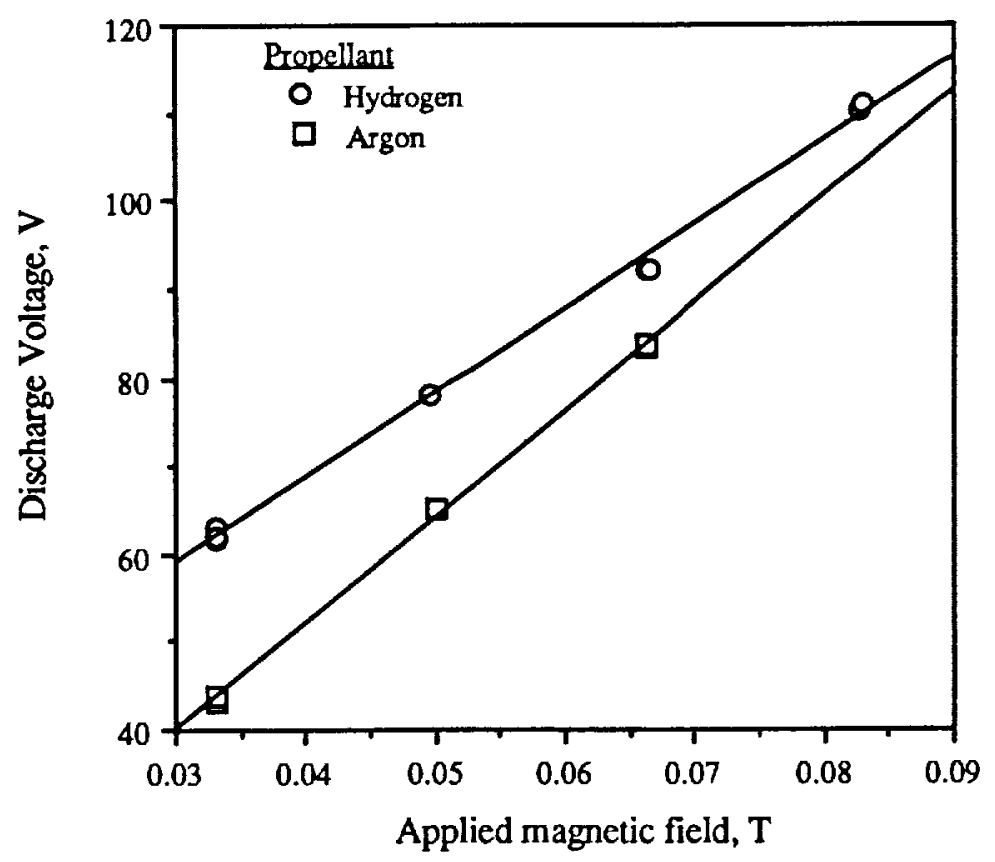

Figure 32. Discharge voltage vs. applied-field strength for hydrogen and argon. Geometry $A, J_{d}=750 \mathrm{~A}, 0.025 \mathrm{~g} / \mathrm{s}$ flow rate. 


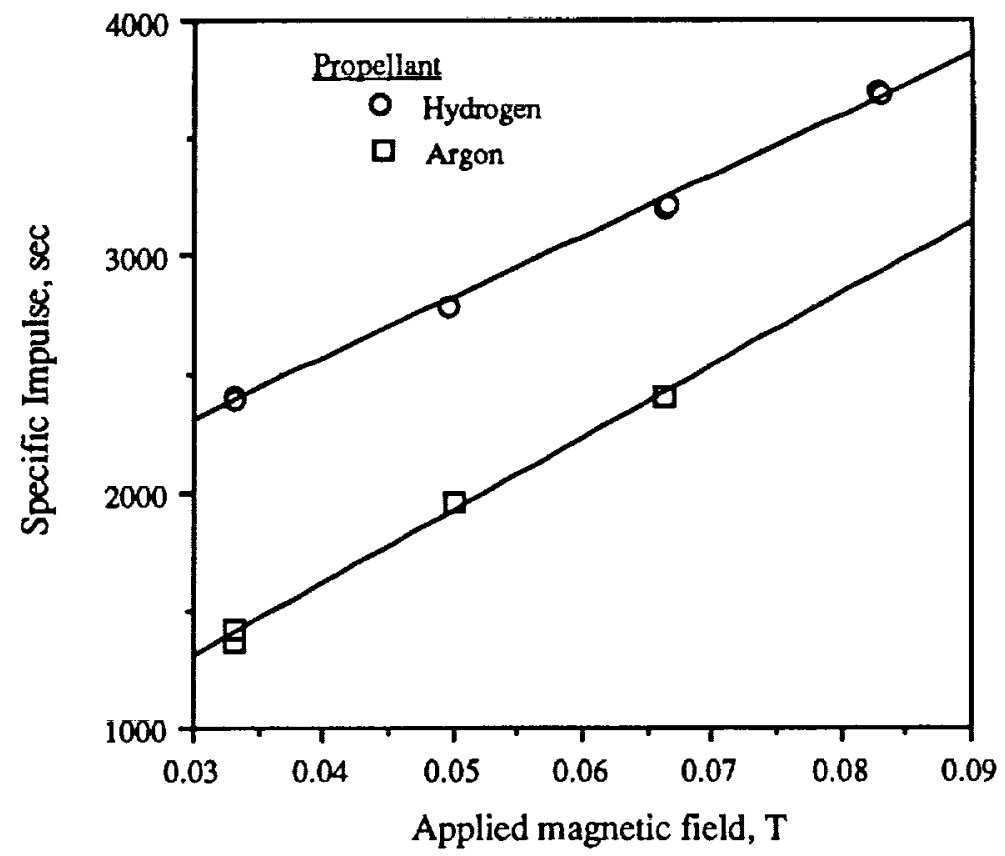

Figure 33. Specific impulse vs. applied-field strength for hydrogen and argon. Geometry $\mathrm{A}, \mathrm{J}_{\mathrm{d}}=750 \mathrm{~A}, 0.025 \mathrm{~g} / \mathrm{s}$ flow rate.

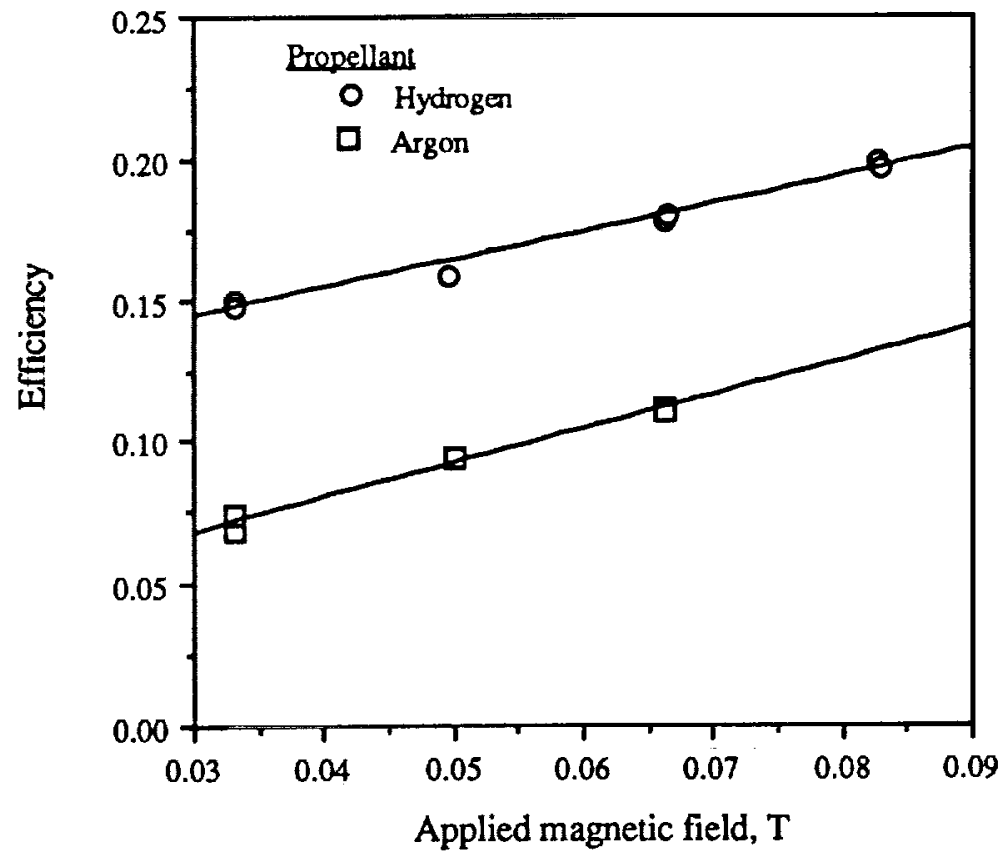

Figure 34. Efficiency vs. applied-field strength for hydrogen and argon. Geometry A, $\mathrm{J}_{\mathrm{d}}=750 \mathrm{~A}, 0.025 \mathrm{~g} / \mathrm{s}$ flow rate. 


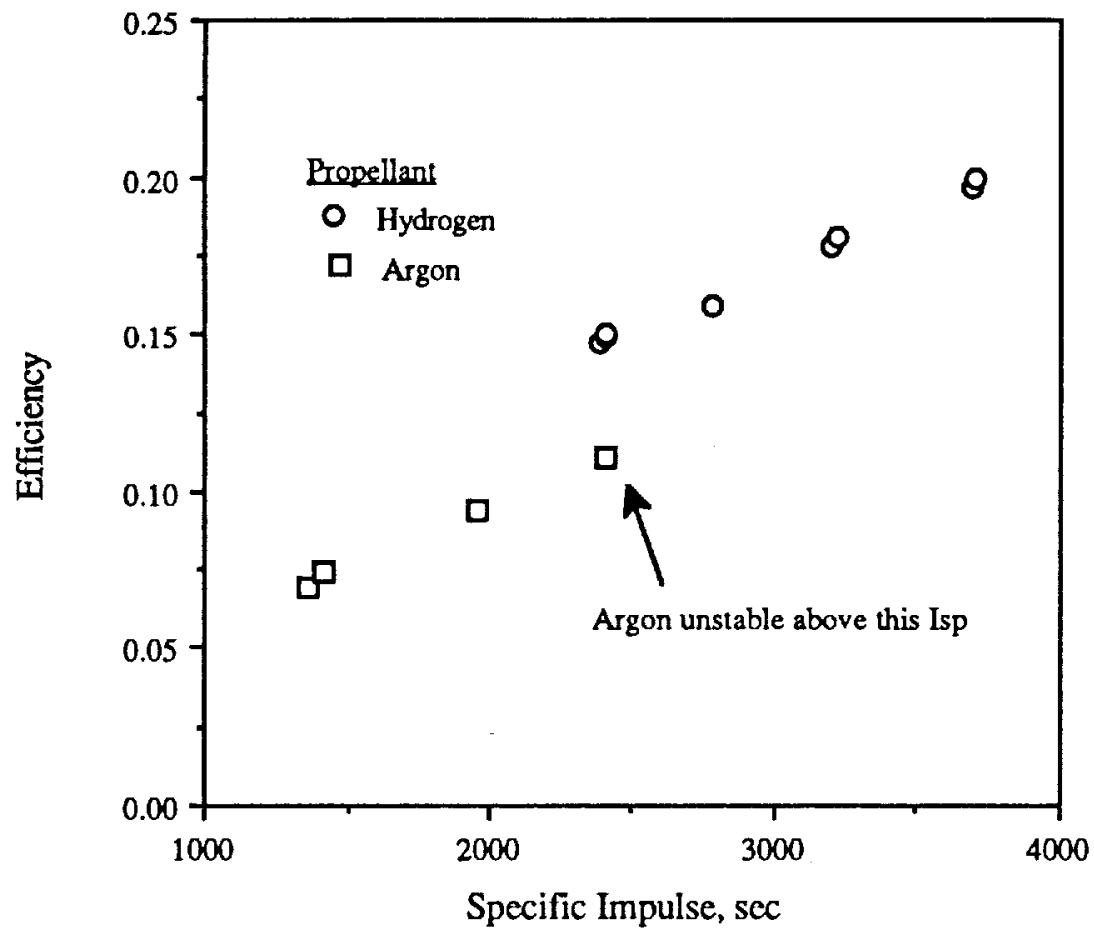

Figure 35. Efficiency vs. specific impulse for hydrogen and argon. Geometry $\mathrm{A}, \mathrm{J}_{\mathrm{d}}=750 \mathrm{~A}, 0.025 \mathrm{~g} / \mathrm{s}$ flow rate.

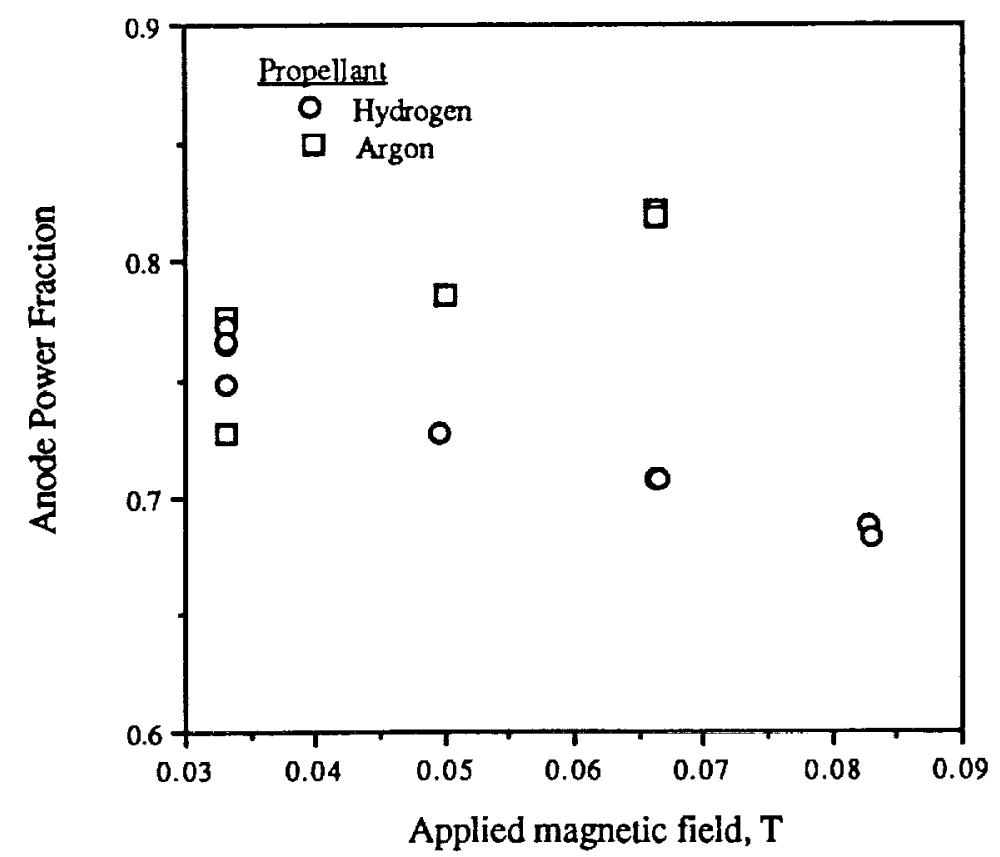

Figure 36. Anode power fraction vs. applied-field strength for hydrogen and argon. Geometry $\mathrm{A}, \mathrm{J}_{\mathrm{d}}=750 \mathrm{~A}, 0.025 \mathrm{~g} / \mathrm{s}$ flow rate. 


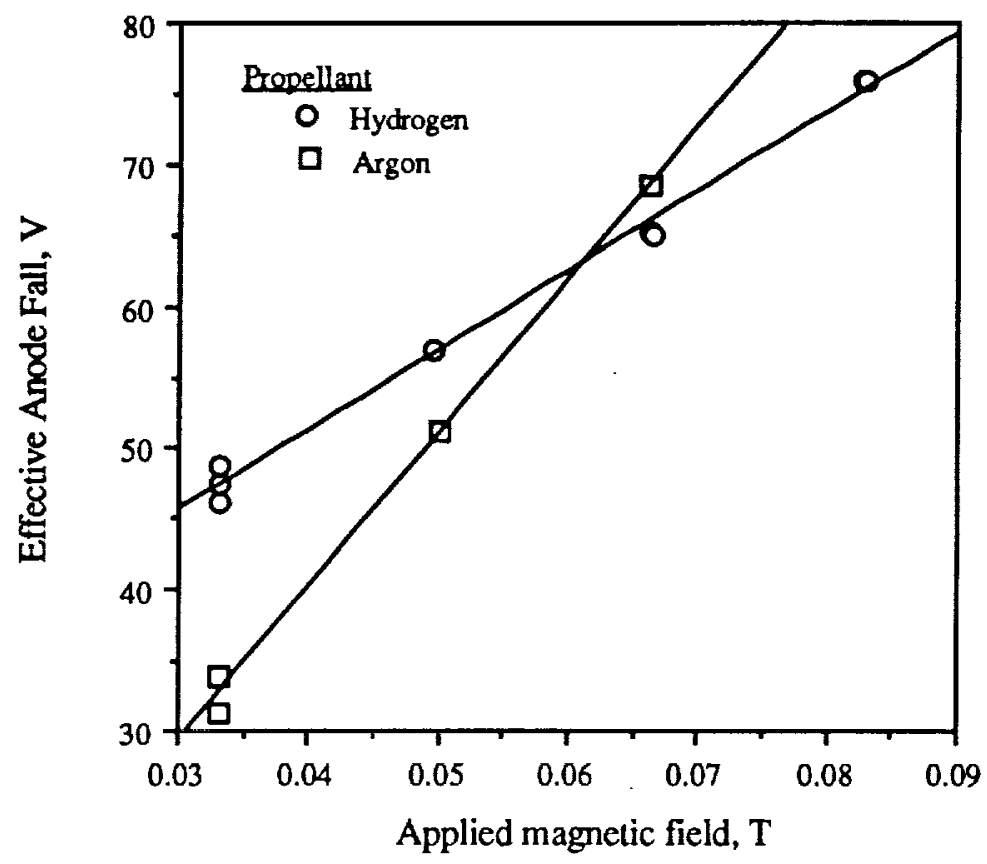

Figure 37. Effective anode fall vs. applied-field strength for hydrogen and argon. Geometry $\mathrm{A}, \mathrm{J}_{\mathrm{u}}=750 \mathrm{~A}, 0.025 \mathrm{~g} / \mathrm{s}$ flow rate. 


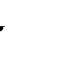




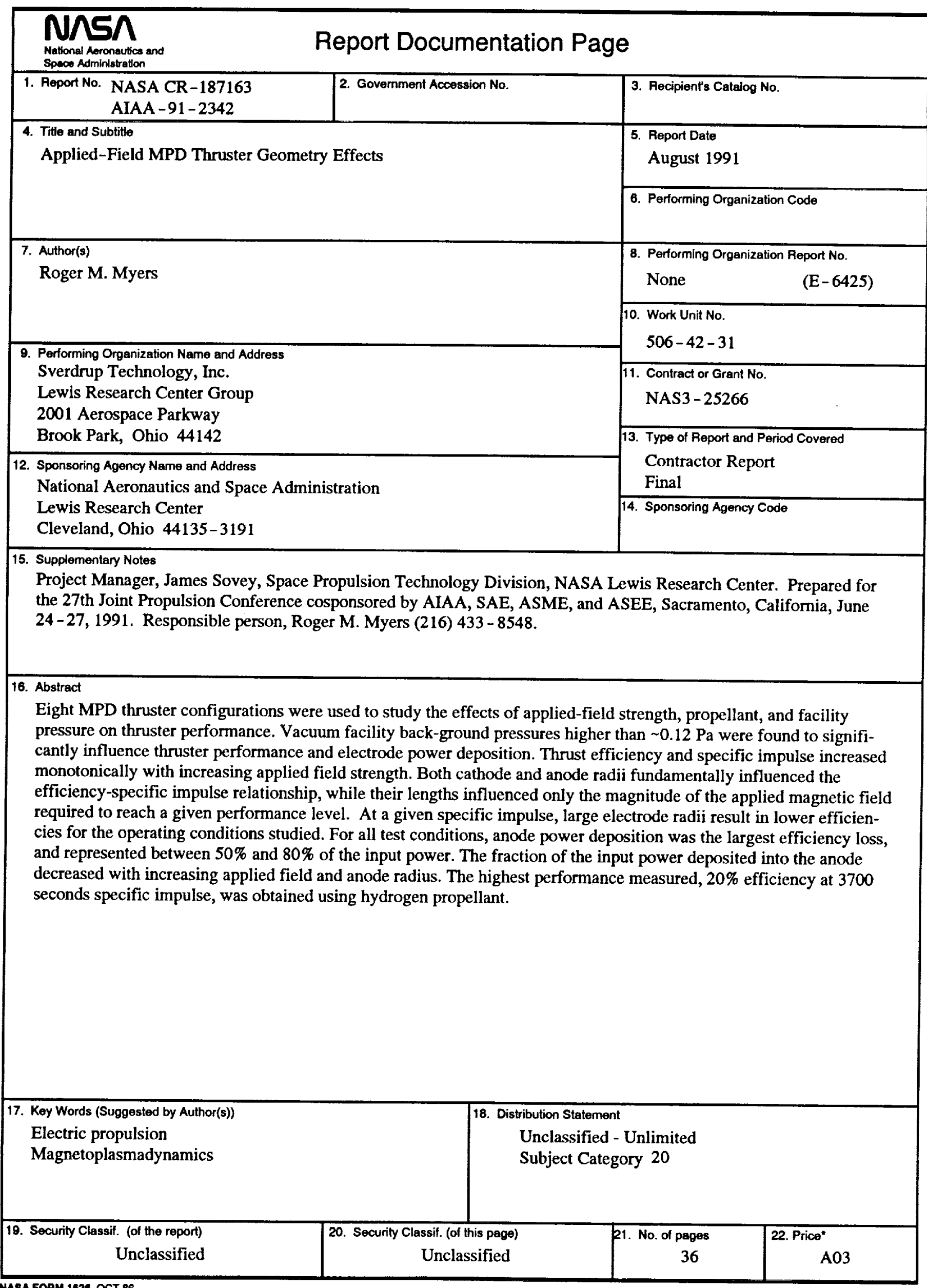

